Louisiana State University

LSU Digital Commons

2014

\title{
Biogeochemical Controls on Biodegradation of MC252 Crude Oil in Coastal Wetland Systems
}

\author{
Matthew Paul Rodrigue \\ Louisiana State University and Agricultural and Mechanical College
}

Follow this and additional works at: https://digitalcommons.Isu.edu/gradschool_theses

Part of the Civil and Environmental Engineering Commons

\section{Recommended Citation}

Rodrigue, Matthew Paul, "Biogeochemical Controls on Biodegradation of MC252 Crude Oil in Coastal Wetland Systems" (2014). LSU Master's Theses. 2971.

https://digitalcommons.Isu.edu/gradschool_theses/2971

This Thesis is brought to you for free and open access by the Graduate School at LSU Digital Commons. It has been accepted for inclusion in LSU Master's Theses by an authorized graduate school editor of LSU Digital Commons. For more information, please contact gradetd@lsu.edu. 


\title{
BIOGEOCHEMICAL CONTROLS ON BIODEGRADATION OF MC252 CRUDE OIL IN COASTAL WETLAND SYSTEMS
}

\author{
A Thesis \\ Submitted to the Graduate Faculty of the \\ Louisiana State University and \\ Agricultural and Mechanical College \\ in partial fulfillment of the \\ requirements for the degree of \\ Masters of Civil Engineering \\ in
}

The Department of Civil and Environmental Engineering

\author{
by \\ Matthew Paul Rodrigue \\ B.S., Louisiana State University, 2012 \\ August 2014
}




\section{ACKNOWLEDGEMENTS}

I would like to thank the governing body of the Edward Wisner Donation for allowing our research team access to their property. I would also like to thank Dr. Michael Blum and his research team at Tulane University for allowing us to hitch hike rides to and from our Bay Jimmy sampling site. Thank you, Dr. John Pardue, for your guidance and companionship over these past three years. I have learned a great deal from you, and I am truly appreciative to have had you as a mentor throughout this process. Also, I would like to thank Dr. William Moe, and Dr. Ronald Malone for setting aside time to join my committee and for being an integral part of my graduate school experience. I would also like to thank my parents, Clark and Debbie Rodrigue, and my fiancée, Lesley Hidalgo for their continued love and support throughout my academic career.

I would also like to thank Dr. Vijai Elango for always taking the time to help me out with research, advice, or just everyday conversation. I wish you the best in your future endeavors. Last but not least, I would like to thank my friends and colleagues that I have had the pleasure to meet and work with throughout my time in graduate school including but not limited to: David, Autumn, Leslie, Yasmin, Michael, Ariel, Allyson, Matt, Mark, Kay, Kendall, Lany, Jacques, Alex, and Chris. 


\section{TABLE OF CONTENTS}

ACKNOWLEDGEMENTS....................................................................................................

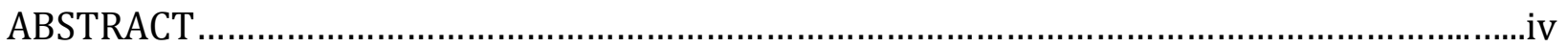

CHAPTER 1: INTRODUCTION AND OUTLINE .................................................................

CHAPTER 2: BIODEGRADATION OF MC252 POLYCYLCIC AROMATIC HYDROCARBONS AND ALKANES IN THREE COASTAL WETLANDS ............................................................

CHAPTER 3: BIODEGRADATION POTENTIAL OF POLYCYCLIC AROMATIC HYDROCARBONS IN COASTAL WETLANDS UNDER DIFFERENT REDOX CONDITIONS........34

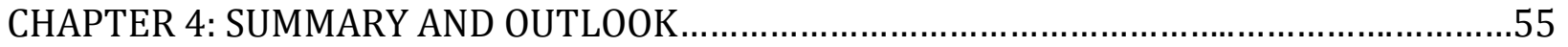

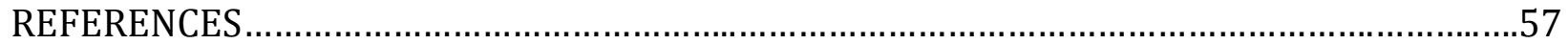

APPENDIX A. PAH WR FROM FOURCHON MARSH FIELD SAMPLES FOR FIGURE 1 .............64

APPENDIX B. ALKANE WR FROM FOURCHON MARSH FIELD SAMPLES FOR FIGURE 1 ......65

APPENDIX C. $\delta^{13} \mathrm{C}$ SIGNATURES IN FOURCHON CORES FROM FIGURE 2.4 ….....................66

APPENDIX D. $\delta^{13} \mathrm{C}$ SIGNATURES IN BAY JIMMY CORES FROM FIGURE $2.4 \ldots \ldots \ldots \ldots \ldots \ldots \ldots \ldots \ldots . . .67$

APPENDIX E. ABBREVIATIONS FOR PAH.......................................................................68

VITA 


\begin{abstract}
Weathering of MC252 oil from the Deepwater Horizon oil spill is taking place in coastal Louisiana marsh and mangrove wetland systems. Alkylated phenanthrenes and dibenzothiophenes, which are the most prominent PAHs found at MC252 contaminated sites, are weathering at rates up to 5\% per year relative to alkylated chrysenes 3 years after initial oiling. Flux chambers at marsh locations trapped $\mathrm{CO}_{2}$ that exhibited $\delta^{13} \mathrm{C}$ signatures lower than indigenous organic matter signifying hydrocarbon mineralization to $\mathrm{CO}_{2}$. Weathering rates at each of these locations are heavily influenced by the biogeochemistry of the surrounding environment. High-resolution nutrient profiles were obtained at different locations within each site during the winter and summer using dialysis samplers. Dialysis sampler results determined that there is an adequate amount of nitrogen and phosphorous in the marsh and mangrove locations to support cell synthesis and enough sulfate to serve as a terminal electron acceptor in the absence of oxygen. Zones of sulfate depletion accompanied by increased ammonia and phosphorous were found in nutrient depth profiles at certain marsh and mangrove locations signifying more anoxic zones in the soils. Aerobic and anaerobic laboratory enrichment cultures were used to observe biodegradation potential of PAHs and n-alkanes in a controlled environment to supplement field findings. In the aerobic enrichment culture experiment, total reduction of n-alkanes and alkylated naphthalenes, fluorenes, phenanthrenes, dibenzothiophenes, and chrysenes were found to be $77,96,93,87,90$, and $47 \%$ after 120 days, respectively, in the Fourchon marsh soil and 51, 92, 93, 83, 84, and 38\% after 120 days, respectively, in the Bay Jimmy marsh soil. First order rate constants for the loss of these alkylated PAHs ranged from 0.88-18 (1/years) for the two sites, with rates decreasing with increased molecular weight
\end{abstract}


and alkylation. Porewater nutrient and electron acceptor data in the anaerobic enrichment cultures indicate microbial activity may be taking place; however, no anaerobic degradation of the aforementioned PAHs were observed over the course of the experiment 


\section{CHAPTER 1: INTRODUCTION AND OUTLINE}

\subsection{Background}

On April 20, 2010, the Deepwater Horizon oil rig, located 77 km offshore at Mississippi Canyon block 252 (MC252), exploded resulting in 11 fatalities and the release of 4.9 million barrels of oil into the Gulf of Mexico(Atlas and Hazen, 2011; Command, 2011). This spill was the largest marine oil spill in United States history, over an order of magnitude larger than the Exxon Valdez oil spill (Atlas and Hazen, 2011; McNutt et al., 2011). The oil was released at a depth of $1.5 \mathrm{~km}$ resulting in the stripping of the more volatile and watersoluble compounds ( 25\%)(Commision, 2011). The remaining hydrocarbons formed a surface slick that made its way to the gulf coast (Aeppli et al., 2012; Reddy et al., 2011; Ryerson et al., 2012). Economic effects were felt throughout the Gulf coast region with the closing of waters to commercial fishing and the oiling of beaches throughout the gulf coast (Hayworth et al., 2011; Upton, 2011; Urbano et al., 2013a).

The sites of interest for this thesis include two oiled sites in Fourchon, LA inland from the Camina beach headlands approximately 110 miles from the site of the Deepwater Horizon blowout as well as a second Louisiana site in Barataria Bay adjacent to Bay Jimmy approximately 103 miles from the blowout (Figure 1.1). Oil reaches the Fourchon tidal marsh system when cold fronts, high tides, and tropical storm systems cause a breach in the headland beach and allow water carrying the hydrocarbon slick into the bay (Georgiou et al., 2005). These breaches termed "washover events" can deposit MC252 oil into the intertidal and supratidal beach zones along with the wetland systems inland form the beach. The two Fourchon sites consist of varying vegetation. One site, the Fourchon marsh site, is dominated by the marsh grass Spartina alterniflora while the other, the Fourchon 


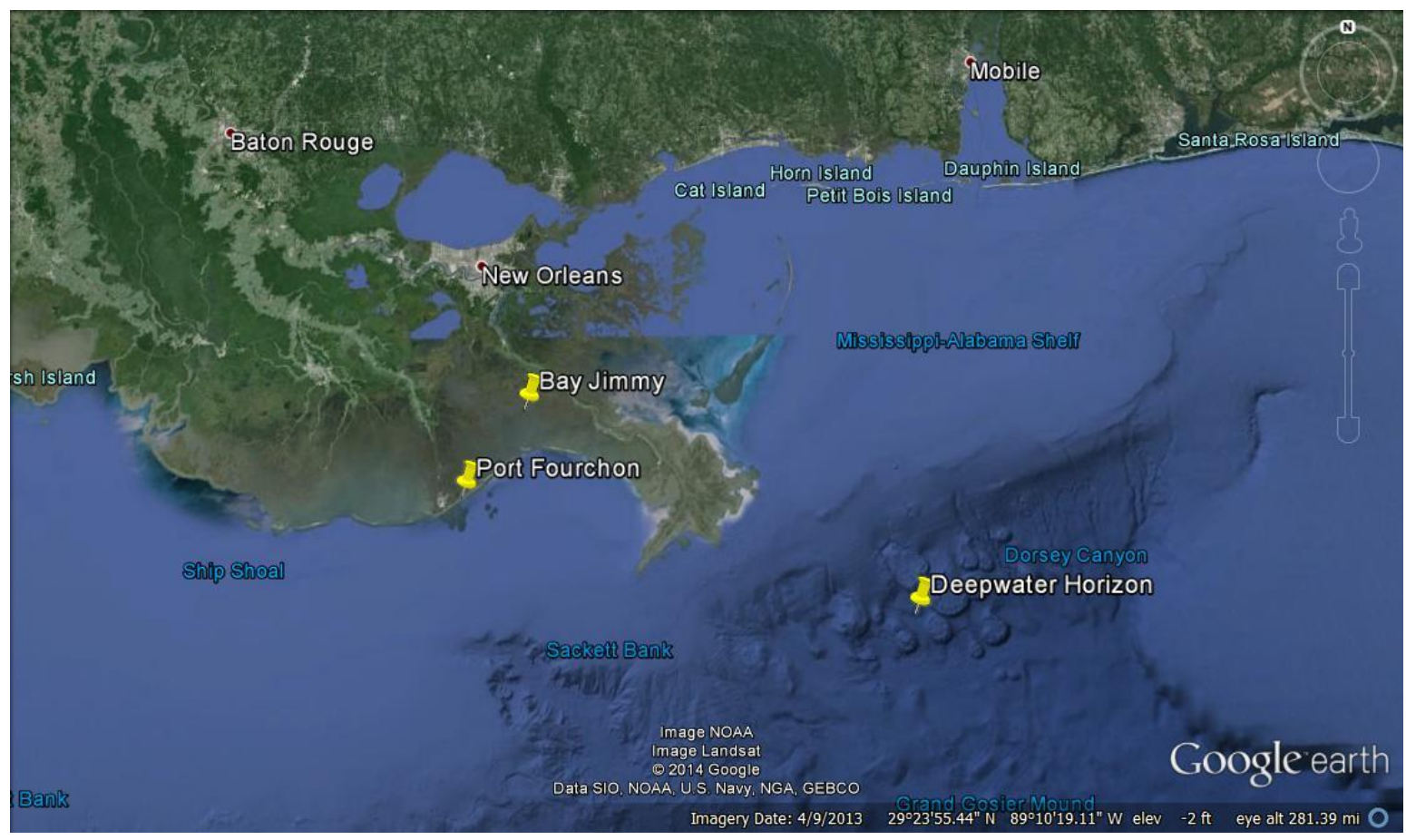

Figure 1.1. Fourchon and Bay Jimmy sampling sites relative to the location of the Deepwater Horizon oil rig

mangrove site, is dominated by Black Mangroves (Avicennia germinan). These two locations are approximately 1000 feet inland from the beach headland and are situated approximately 200 feet apart (Figure 1.2) . The Bay Jimmy site, also dominated by Spartina alterniflora, was more heavily contaminated by the incoming oil because of the lack of a headland beach barrier at that location (Figure 1.3). Oiling at this location was highly variable depending on the location and elevation of the shoreline. The contaminated Bay Jimmy shoreline is constantly being eroded due to sediment compaction and rising seas levels. MC252 oil was washed into the marshes situated at lower elevations while higher elevation marshes were oiled to a much lesser degree.

Petroleum components are classified into 4 groups: saturates, aromatics, resins, and asphaltenes. Of all the components of MC252 oil, aromatics in the form of polycyclic aromatic hydrocarbons (PAHs) and saturates in the form of n-alkanes are of particular 


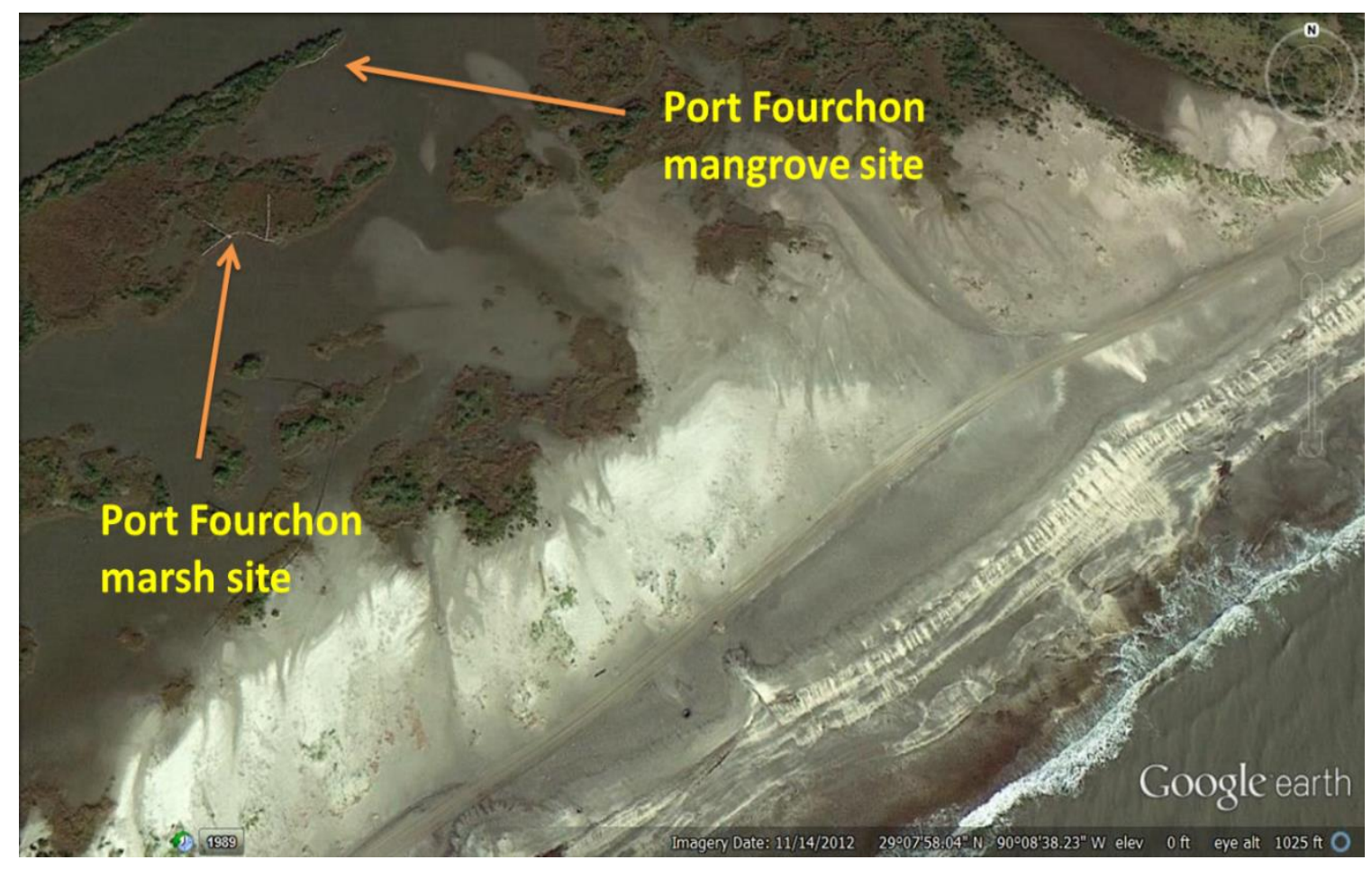

Figure 1.2. Fourchon, LA sampling sites

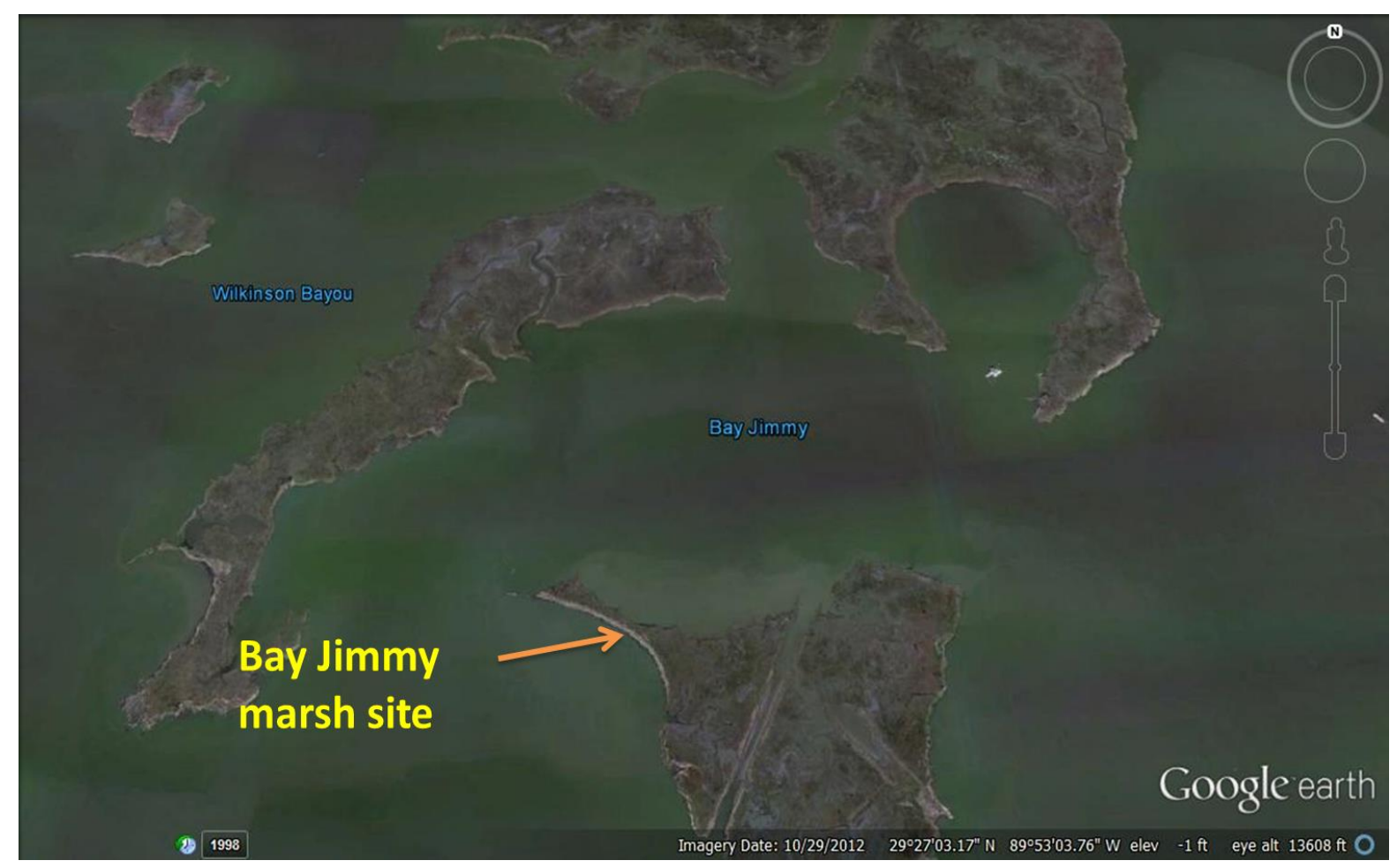

Figure 1.3. Bay Jimmy sampling site 
interest for this study. PAHs are a group of hazardous, organic chemicals which have two or more fused benzene rings in a linear, angular, or clustered arrangement (Cerniglia, 1992). Most PAHs occur naturally and therefore have been involved in naturally occurring processes for millions of years explaining the ability of microorganisms to utilize these natural hydrocarbons as a carbon source (Gibson, 1984). Persistence in the environment is the main concern of PAHs because they have low water solubility causing them to accumulate in sediments until they are degraded, re-suspended, or removed mechanically(Cerniglia, 1992). The degradation rates of PAHs are inversely proportional to the number of rings in the PAH molecule with lower weights being degraded more quickly that heavier PAHs (Cerniglia and Heitkamp, 1989). Likewise, degradation rates are also inversely proportional to levels of alkylation within parent PAH compounds (Cerniglia, 1993; Wang et al., 1998). N-alkanes are hydrocarbons consisting of a chain of single bonded carbon and are generally regarded as the most readily degradable components of oil (Atlas, 1981; Venosa and Zhu, 2003). Degradation rates decrease as the length of the carbon chains increase within this group (Leahy and Colwell, 1990; Wang et al., 1998).

To confirm or disprove biodegradation of MC252 oil at each location, stable carbon isotope ratios of the evolved $\mathrm{CO}_{2}$ were determined. Carbon dioxide has varying ratios of C13 to C12 in accordance with the source of the gas (Jackson et al., 1996). This ratio can be expressed relative to a standard and expressed as a $\delta^{13} \mathrm{C}$ value. Equation 1.1 shows the calculation of this value. The standard used in this calculation is carbonate from Pee Dee belemnite limestone. $\delta^{13} \mathrm{C}$ signatures are reported in units of per mille (\%o). Plants are grouped as C3 and C4 plants according to pathways used for carbon fixation. C3 plants utilize the Calvin cycle and have lower (more negative) $\delta^{13} \mathrm{C}$ signatures ranging from -24 to 
$-34 \%$. C4 plants, common to coastal Louisiana marsh systems, utilize an additional pathway known as the Hatch-Slack pathway(Chmura et al., 1987). These plants have higher (less negative) $\delta^{13} \mathrm{C}$ signatures ranging from - 6 to $-19 \%$. Evolved $\mathrm{CO}_{2}$ from hydrocarbons are more depleted in ${ }^{13} \mathrm{C}$, thus yielding a more negative $\delta^{13} \mathrm{C}$ value. The difference in ${ }^{13} \mathrm{C}$ signature between $\mathrm{C} 4$ plants and hydrocarbons allows for the detection and quantification of hydrocarbon mineralization (Jackson et al., 1996).

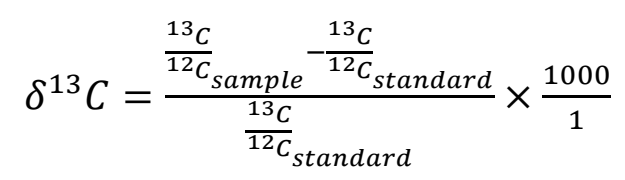

Biogeochemical controls at MC252-contaminated sites are important factors controlling degradation rates. One important biogeochemical control is the redox potential of the system. Microbial processes which use oxygen as an electron acceptor can account for a large portion of hydrocarbon degradation; however, oxygen demand in a coastal salt marsh system is high due to cellular respiration and oxidation of sulfide while oxygen availability is low due to flooded conditions (Atlas, 1981; Rockne and Strand, 1998; Shin et al., 2001). In oil contaminated salt marsh systems such as Fourchon and Bay Jimmy, there is an abundance of sulfate which has been shown the ability to be used as a terminal electron acceptor by hydrocarbon degrading bacteria in prior studies (Annweiler et al., 2000; Bergmann et al., 2011; Hayes and Lovley, 2002; Rockne and Strand, 1998; Shin et al., 2000). Nutrients, such as nitrogen and phosphorous, needed for cell synthesis can also become rate limiting in these marsh systems. Several prior studies have shown trends of increased hydrocarbon biodegradation rates with increased nitrogen and phosphorous 
concentrations (Jackson and Pardue, 1999b; Mercer and Trevors, 2011; Santos et al., 2011; Tate et al., 2012).

Laboratory enrichment culture studies under different redox potentials in prior studies have yielded varying levels of PAH and n-alkane biodegradation potential in salt marsh soils. Aerobic microbial degradation of unsubstituted 2-, 3- and 4-ring PAHs has been reported in numerous studies (Bauer and Capone, 1985; Lei et al., 2005; McNally et al., 1998; Shin et al., 2001). Increased alkylation of these PAHs lead to reduced rates and ability of microbial degradation (Chen et al., 2013). Reduction of these methyl substituted PAHs in prior studies has been attributed to aerobic microbial degradation (Bayona et al., 1986). Anaerobic biodegradation of PAHs has also been observed in some instances under nitrate and sulfate reducing conditions. Most of these studies are limited to unsubstituted 2-ring PAHs (Bauer and Capone, 1985; Coates et al., 1996; Rockne et al., 2000; Rockne and Strand, 1998; Zhang et al., 2000). To date, methyl substituted 2-, 3-, and 4-ring PAHs have been reported to be very persistent under anaerobic conditions (Peacock et al., 2007).

\subsection{Research Objectives}

The objectives of this research were to:

1. Observe $\mathrm{PAH}$ and $\mathrm{n}$-alkane degradation by changes in weathering ratios over time in MC252 oiled marsh and mangrove sediments at the Bay Jimmy and Fourchon locations.

2. Determine if changes in weathering ratios of oil components can be attributed to oil mineralization using stable carbon isotope method.

3. Observe porewater nutrient and electron acceptor concentrations at depth to determine if the marsh and mangrove locations could support biodegradation. 
4. Observe weather ratios of oil components in laboratory enrichment cultures to determine the aerobic and anaerobic biodegradation potential of MC252 oil in marsh and mangrove soils.

Objectives 1,2, and 3 will be addressed in Chapter 2 and objective 4 will be addressed in Chapter 3.

\subsection{Environmental Relevance of the Study}

The research in this thesis is designed to observe the long term effect of oil from the Deepwater Horizon oil spill in marsh and mangrove wetlands in coastal Louisiana. These oil contaminated wetlands are a vital ecosystem in direct contact with aquatic and terrestrial organisms, posing a direct threat to the animals and a more indirect threat to humans due to these hazardous hydrocarbon compounds potentially making their way into the food chain. Specifically, this thesis will focus on the persistence and fate of oil, particularly PAH and n-alkanes, in these fragile wetland systems. Contamination of these salt marsh and mangrove systems from the oil spill provided the opportunity to observe and better understand the weathering and more specifically the biodegradation potential of these coastal systems at a scale never before witnessed in this region. Previous hydrocarbon biodegradation research was limited to intentional or accidental, lightlycontaminated wetlands or laboratory enrichment culture experiments. Knowledge gained from this thesis combine with other MC252 oil-related research currently taking place may prove useful in future oil spill response and cleanup. The long-term fate of MC252 oil constituents in these coastal wetland systems is largely unknown and will be the focus of research for years to come. 


\subsection{Organization of this Thesis}

Chapter 2 investigates weathering taking place at marsh and mangrove sites in Fourchon and Bay Jimmy, Louisiana. This chapter also investigates what percentage of the weathering can be attributed to biodegradation as well as the impacts of some biogeochemical controls on biodegradation. Chapter 3 observes the biodegradation potential of MC252 oil in Fourchon marsh and mangrove soils as well as in Bay Jimmy marsh soils under various redox potentials. The final chapter, Chapter 4 recaps the results from chapters 2 and 3 and highlights some areas for future research. 


\section{CHAPTER 2: BIODEGRADATION OF MC252 POLYCYLCIC AROMATIC HYDROCARBONS AND ALKANES IN THREE COASTAL WETLANDS}

\subsection{Introduction}

In May of 2010, MC252 oil from the blown out Macondo well began to reach the coastal wetlands of southern Louisiana. Marsh and mangrove wetlands were contaminated when a floating, water-in-oil emulsion, depleted of the more volatile petroleum components, was transported onto the Louisiana shoreline, partially driven by tropical storms during the summer of 2010 . Of the $1773 \mathrm{~km}$ of oiled shoreline, $45 \%$ were classified as marshes, yet cleanup activities were only authorized on $68 \mathrm{~km}$ or $4 \%$ of the total oiled shoreline (Michel et al., 2013). Traditional mechanical cleanup of oiled sediments in these marsh areas are relatively inefficient and can be more harmful to the ecosystem than the oiling (Venosa and Zhu, 2003; Yu et al., 2012). As a result, a disproportionate importance was placed on the natural recovery of oiled marshes and associated habitats over sand beaches.

To date, studies on MC252-impacted marshes have examined recovery of plant structure and function (Anderson and Hess, 2012; Lin and Mendelssohn, 2012), rates of erosion (McClenachan et al., 2013) and impacts on marsh organisms (Moody et al., 2013; Whitehead et al., 2012). Studies that have directly examined the fate of crude oil components in these marshes reported relatively rapid loss of alkanes and polycyclic aromatic hydrocarbons (PAHs), attributed to biodegradation, over the first year after the spill (Mahmoudi et al., 2013; Silliman et al., 2012). These results are in contrast to Barataria Bay, LA marsh areas that remain in active response, due to the continuing presence of oil, more than 3 years after the spill. The rapid disappearance of these 
compounds is also inconsistent with previous studies that demonstrate long-term persistence of oil in salt marsh environments (Peacock et al., 2007).

The natural weathering of oil in contaminated marshes involves volatilization, dispersion, and biodegradation processes, among others. Biodegradation potential of crude oil in marshes depends on the magnitude and type of oil present, the availability of electron acceptors, the presence of nutrients (nitrogen and phosphorous), and the presence of hydrocarbon-degrading bacteria (Mendelssohn et al., 2012). Oxygen can be limiting in marshes and PAHs are not likely to undergo substantial microbial degradation in anaerobic sediments where they can persist for decades.(Mendelssohn et al., 2012; Peacock et al., 2007). Tidal fluctuations expose a portion of the marsh surface and oxygen can potentially be present near the surface. Deeper in the bed, sulfate dominates (Canfield et al., 1993; Coates et al., 1996) and hydrocarbon-degrading, sulfate-reducing bacteria have been reported making it the most likely process for anaerobic hydrocarbon degradation (McGenity, 2014; Shin et al., 2000; Widdel et al., 2010). Nutrient availability can also vary seasonally (Venosa and Zhu, 2003) and ultimately $150 \mathrm{mg}$ of nitrogen and $30 \mathrm{mg}$ of phosphorous are required for every gram of hydrocarbons converted to cell matter.

Mineralization of crude oil components to $\mathrm{CO}_{2}$ is the preferred weathering process, when possible, because the contaminants are removed from the system rather than transferred to another phase (Jackson and Pardue, 1999b; Leahy and Colwell, 1990). Mineralization of crude oil can be directly measured in salt marshes due to differences in $\delta^{13} \mathrm{C}$ signature in petroleum and the C4 plants (i.e., Spartina alterniflora) that dominate these ecosystems (Jackson and Pardue, 1999a; Jackson et al., 1996). ${ }^{13 C}$-depleted crude oils have signatures ranging from -20\%o to -31\%o (Deines et al., 1980; Jackson and Pardue, 
1999a; Jackson et al., 1996) while MC252 crude has a $\delta^{13} \mathrm{C}$ signature of $-27 \pm 0.2 \%$ (Natter et al., 2012). The $\delta^{13} \mathrm{C}$ signature values of $\mathrm{C} 4$ plants range from $-14.4 \%$ to $-17.7 \%$ o differing drastically from that of the petroleum hydrocarbons.

In this study, MC252 oil weathering, mineralization and nutrient availability were investigated in 3 distinct coastal marsh and mangrove wetlands impacted by oil from the spill. Data were collected over the time frame of 2012-2013, which represents a timeframe of 2-3 years after oil reached the shoreline. Three complimentary techniques were used to explore the rate and extent of weathering: 1) chemical analysis of individual PAHs over time, 2) measurements of $\mathrm{CO}_{2}$ flux from the marsh surface coupled with determination of the $\delta^{13} \mathrm{C}$ of the evolved gas, the bulk soil and the plant root matter, and 3) high-resolution dialysis sampler measurements of porewater nutrients and sulfate concentrations. Taken together, these data are used to assess the rate of weathering in these wetlands over this time timeframe, specifically focused on biodegradation. The overall goal of the study is to determine the rate and extent of weathering in wetlands with different oil loading history and understand the mechanisms involved in PAH and alkane loss.

\subsection{Materials and Methods}

\subsubsection{Site Description}

Measurements were conducted at three coastal wetland sites of interest; a marsh site on the southern border of Bay Jimmy $\left(29^{\circ} 26^{\prime} 38.13^{\prime \prime}\right.$ N, $\left.89^{\circ} 55^{\prime} 15.92^{\prime \prime} \mathrm{W}\right)$ in Plaquemines Parish, LA approximately 12 miles WSW of Port Sulphur at, a marsh site just inland of Fourchon Beach $\left(29^{\circ} 08^{\prime} 00.13^{\prime \prime}\right.$ N, $90^{\circ} 08^{\prime} 43.59^{\prime \prime}$ W) in Lafourche Parish, LA dominated by Spartina alterniflora, and an adjacent mangrove site also inland of Fourchon Beach dominated by 
Avicennia germinans. Both the Bay Jimmy site and the Fourchon sites were contaminated by MC252 oil from the Macondo well blowout located approximately 105 miles and 111 miles away, respectively. Boardwalks were installed at the Fourchon sites that allowed sampling with minimal disturbance of the oiled shoreline. The Bay Jimmy site allowed experimentation by walking along a designated travel corridor landward of shoreline plots, minimizing shoreline damage.

\subsubsection{Core sampling}

At various shoreline and inland locations of each wetland site, grab samples from the surface (0-5 cm depth) and $15 \mathrm{~cm}$ diameter cores $(0-25 \mathrm{~cm}$ depth) were taken from 08/11/2011 to $11 / 17 / 2013$ to determine the mass and chemical characteristics of oil present. Grab samples were collected with a clean trowel, placed in glass jars, homogenized, and stored at $3^{\circ} \mathrm{C}$ prior to extraction and analysis. Core samples were sectioned, homogenized within each section, and a $10 \mathrm{~g}$ subsample was taken for oil extraction.

\subsubsection{Crude oil mineralization using $\delta^{13} \mathrm{C}-\mathrm{CO}_{2}$}

Carbon dioxide fluxes $\left(\mathrm{mg} / \mathrm{m}^{2}-\mathrm{d}\right)$ and the $\delta^{13} \mathrm{C}$ signature of the evolved $\mathrm{CO}_{2}$ were measured at the Fourchon and the Bay Jimmy marsh sites (Jackson and Pardue, 1999a; Jackson et al., 1996). These locations represent areas of different oil loading and were designed to test the sensitivity of the method. Flux chambers were installed on the shoreline as well as locations inland from the shore. The $\mathrm{CO}_{2}$ flux chambers consisted of a section of $20 \mathrm{~cm}$ diameter PVC pipe inserted into the marsh. The PVC had 2 holes drilled into the side to allow for tidal exchange. During flux measurements, a PVC cap was placed 
on the chamber to isolate the marsh surface. Inside each trap hung a beaker containing approximately $20 \mathrm{~mL}$ of $1 \mathrm{M} \mathrm{NaOH}$ to trap the $\mathrm{CO}_{2}$. At the initiation of measurements, chambers were purged with $\mathrm{CO}_{2}$-free air (Airgas Inc.) for 1 minute prior to capping to assure that all internal $\mathrm{CO}_{2}$ was generated during the sampling period. After a 5-hour incubation time, the $\mathrm{NaOH}$ was removed, the solution capped, stored on ice, and brought back to the lab for analysis.

To precipitate out the trapped carbon, $5 \mathrm{~mL}$ of $1 \mathrm{M}$ barium chloride was added to the $\mathrm{NaOH}$ solution removed from the trap. Solid $\mathrm{BaCO}_{3}$ was removed via centrifugation and sent to Geochron Laboratories (Chelmsford, MA) for the determination of the $\delta^{13} \mathrm{C}$ signature of the carbonate using natural abundance mass spectrometry. The molar mass of $\mathrm{CO}_{2}$ captured in each trap was determined by titrating the supernatant with $1 \mathrm{M}$ hydrochloric acid quantified using eq. 2.1

$$
\mathrm{CO}_{2}(\text { in trap })=0.5 \times\left(\frac{\mathrm{V}_{\mathrm{NaOH}} \times \mathrm{C}_{\mathrm{NaOH}}}{1000}-\frac{\mathrm{V}_{\mathrm{HCl}} \times \mathrm{C}_{\mathrm{HCl}}}{1000}\right)
$$

where $\mathrm{V}_{\mathrm{NaOH}}$ is the volume of $\mathrm{NaOH}$ from the trap $(\mathrm{mL}), \mathrm{C}_{\mathrm{NaOH}}$ is the molar concentration of $\mathrm{NaOH}$ in the trap, $\mathrm{V}_{\mathrm{HCl}}$ is the volume of $\mathrm{HCl}$ used in the titration $(\mathrm{mL})$ and $\mathrm{C}_{\mathrm{HCl}}$ is the molar concentration of $\mathrm{HCl}$ used in the titration.

The rate of $\mathrm{CO} 2$ production from MC252 oil mineralization can be differentiated from that of the indigenous carbon mineralization using equations 2.2 and 2.3 (Jackson et al., 1996).

$$
\frac{R_{0}}{R_{t}}\left(S_{o}\right)+\frac{R_{i}}{R_{t}}\left(S_{i}\right)=S_{t}
$$




$$
\frac{R_{o}}{R_{t}}+\frac{R_{i}}{R_{t}}=1
$$

$\mathrm{R}_{\mathrm{o}}$ and $\mathrm{R}_{\mathrm{i}}$ are rates of $\mathrm{CO}_{2}$ production from oil and indigenous organic carbon, respectively. $\mathrm{R}_{\mathrm{t}}$ is the total rate of $\mathrm{CO}_{2}$ production. $\mathrm{S}_{\mathrm{o}}$ and $\mathrm{S}_{\mathrm{i}}$ are the $\delta^{13} \mathrm{C}$ signatures of hydrocarbons and the indigenous organic carbon, respectively. $\mathrm{S}_{\mathrm{t}}$ is overall $\delta^{13} \mathrm{C}$ signature of the total carbon produced. $R_{t}, S_{0}, S_{i}$, and $S_{t}$ were determined experimentally, which leaves a solvable set of 2 independent equations and 2 unknown variables, $R_{o}$ and $R_{i}$. The So value was determined to be $-27 \pm 0.2$ for MC252 (Natter et al., 2012). The term $S_{i}$ was determined by taking a core inland from the chambers in an area where little to no oil was observed. The top $5 \mathrm{~cm}$ of the core was extracted with a 50:50 mixture of hexane and acetone to remove any oil that may be present using methods described below. The $\delta^{13} \mathrm{C}$ signature of the top section after extraction was then determined and used as a baseline signature of the indigenous organic matter.

The $\delta^{13} \mathrm{C}$ signatures of the soil and root matter were determined at $5 \mathrm{~cm}$ intervals in 25 cm long, $15 \mathrm{~cm}$ diameter cores taken at the Fourchon and Bay Jimmy marsh sites. Each 5 cm section was separated into 1 of 3 subsamples: bulk soil (no sieving), soil with root matter removed (material which passed through a No. 40 sieve), and root matter (organic matter retained on a No. 40 sieve) (Figure 2.1). Each subsample was dried overnight at $105^{\circ} \mathrm{C}$ and then separated into two parts: an oiled sample (analyzed as is) and washed (crude oil extracted). Oil was extracted from washed samples with a hexane:acetone (50:50) solvent by mixing for 24 hours in a tumbler followed by a DI water rinse. The extract from the bulk soil was concentrated and analyzed for PAHs and n-alkanes. This extraction process was the then repeated to further wash the samples and the extract was 


\begin{abstract}
A) Separate bulk core into $55-\mathrm{cm}$ sections
\end{abstract}

B) Separated each section into the following subsamples
C) Wash oil from half of each subsample, leave other half oiled

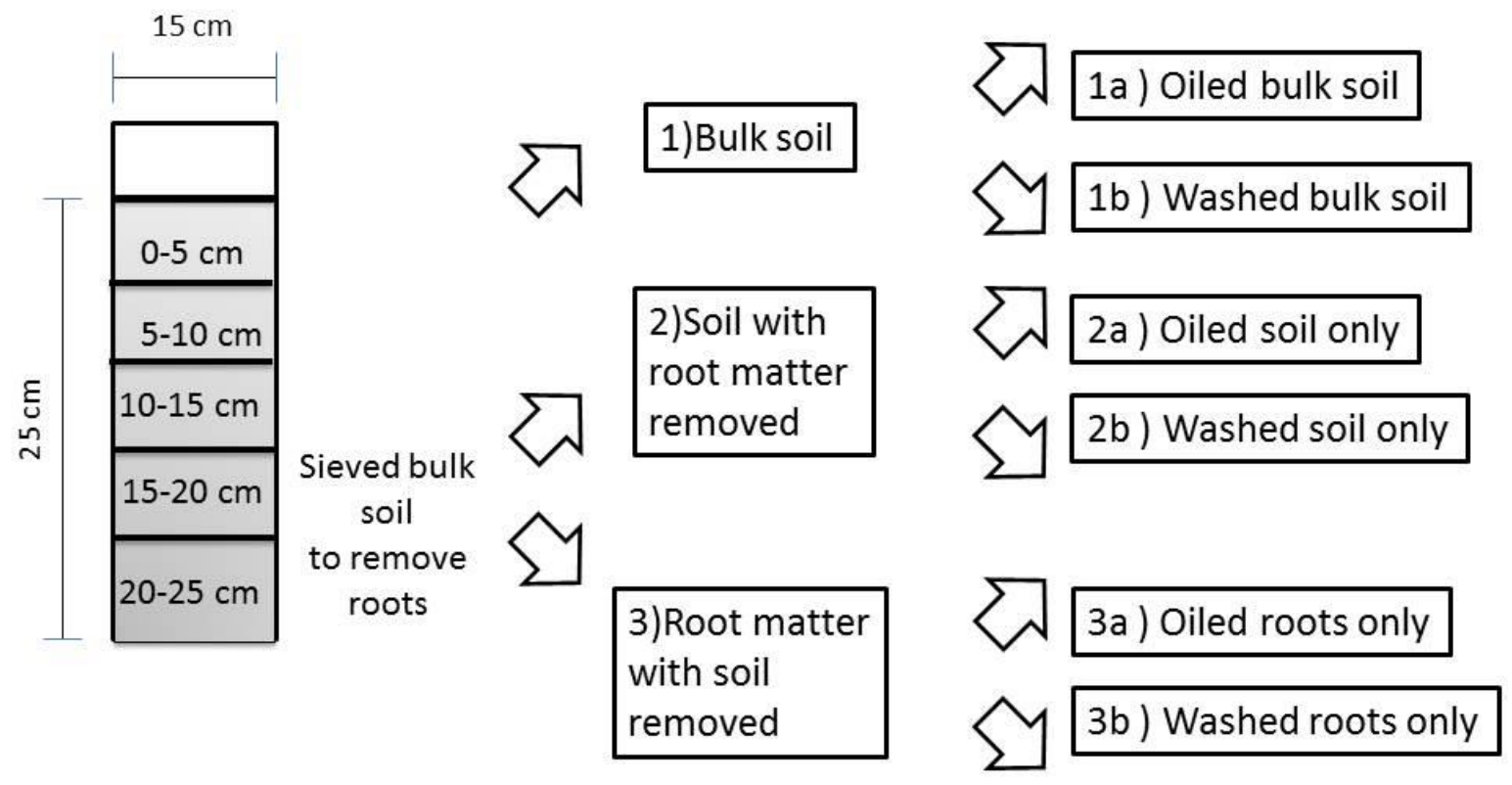

Figure 2.1. Core processing performed to obtain $\delta^{13} \mathrm{C}$ signatures of soil and root matter at depth

discarded. The oiled samples did not undergo any oil extraction. Samples were dried, ground to a fine powder, and analyzed for $\delta^{13} \mathrm{C}$ using a natural abundance ratio mass spectrometer.

\subsubsection{Nutrient porewater profiles}

Sampling of the porewater at each location was performed using $2.5 \mathrm{ft}$.-long dialysis samplers constructed from Plexiglass (Hesslein, 1976). Dialysis samplers or "peepers" were constructed to allow for diffusion-based sampling of porewater constituents across a membrane into "cells" or chambers machined into the Plexiglass blocks. The cells were pre-filled with deionized water and covered by HT-200 $0.2 \mu \mathrm{m}$ pore size membrane (Pall 
Corporation). Samplers were inserted vertically into marsh and mangrove locations and incubated in place for approximately 1 month.

During the retrieval process, water from select cells was removed using a syringe, placed into $1.5 \mathrm{~mL}$ Agilent screw-top vials, and stored on ice until laboratory analysis. In the lab, samples were stored no longer than 1 week at $3^{\circ} \mathrm{C}$ before analysis. A SmartChem 170 Discrete Analyzer (Unity Scientific Inc.) was used to measure nitrate $\left(\mathrm{NO}_{3}^{-}\right)$, nitrite $\left(\mathrm{NO}_{2}^{-}\right)$, orthophosphates $\left(\mathrm{PO}_{4}^{3-}\right)$, ammonium $\left(\mathrm{NH}_{4}{ }^{+}\right)$, and sulfate $\left(\mathrm{SO}_{4}{ }^{2-}\right)$ concentrations using EPA methods \#353.2, 353.3, 365.1, 350.1 and 375.4, respectively. QA/QC included blanks and 5-point calibration before every run.

\subsubsection{PAH and n-alkane extraction and analysis}

Oil constituents were extracted from soil using a Dionex Accelerated Solvent Extractor 350 (Thermo Scientific). Subsamples of oiled sediments were mixed with sodium sulfate and magnesium sulfate to remove moisture before extraction. The extractor pressurized and heated sediment mixtures to $1700 \mathrm{PSI}$ and $100^{\circ} \mathrm{C}$ while extracting oil components with a 50:50 mixture of hexane and acetone as the solvent. The extract was concentrated down to $10 \mathrm{ml}$ using a RapidVac $\mathrm{N}_{2}$ Evaporation System (Labconco, USA). One $\mu \mathrm{l}$ of each sample was injected onto a Hewlett Packard 6890N gas chromatograph equipped with a HP series autosampler, DB 5 capillary column (30m x 0.25mm x $0.25 \mu \mathrm{m}$ film) and HP 5973 mass selective detector. The temperature program for the analysis was as follows: injector set to $300^{\circ} \mathrm{C}$, detector set to $280^{\circ} \mathrm{C}$, and oven temperature set to $45^{\circ} \mathrm{C}$ for $3 \mathrm{~min}$ then increased at $6^{\circ} \mathrm{C} / \mathrm{min}$ to $315^{\circ} \mathrm{C}$ and held for $15 \mathrm{~min}$. Helium $(5.7 \mathrm{~mL} / \mathrm{min})$ was used as the carrier gas. Quantification was performed in selected ion monitoring mode using internal standards. 
PAHs quantitated include: naphthalene $\left(\mathrm{C}_{0} \mathrm{~N}\right)$, C1-naphthalenes $\left(\mathrm{C}_{1} \mathrm{~N}\right), \mathrm{C} 2$-naphthalenes $\left(\mathrm{C}_{2} \mathrm{~N}\right)$, C3-naphthalenes $\left(\mathrm{C}_{3} \mathrm{~N}\right)$, C4-naphthalenes $\left(\mathrm{C}_{4} \mathrm{~N}\right)$, fluorene $\left(\mathrm{C}_{0} \mathrm{~F}\right)$, C1-fluorenes $\left(\mathrm{C}_{1} \mathrm{~F}\right)$, C2-fluorenes $\left(\mathrm{C}_{2} \mathrm{~F}\right)$, C3-fluorenes $\left(\mathrm{C}_{3} \mathrm{~F}\right)$ phenanthrene $\left(\mathrm{C}_{0} \mathrm{P}\right)$, C1-phenanthrenes $\left(\mathrm{C}_{1} \mathrm{P}\right), \mathrm{C} 2$ -

phenanthrenes $\left(\mathrm{C}_{2} \mathrm{P}\right)$, C3-phenanthrenes $\left(\mathrm{C}_{3} \mathrm{P}\right)$, C4-phenanthrenes $\left(\mathrm{C}_{4} \mathrm{P}\right)$, dibenzothiophene $\left(\mathrm{C}_{0} \mathrm{D}\right), \mathrm{C} 1$-dibenzothiophenes $\left(\mathrm{C}_{1} \mathrm{D}\right), \mathrm{C} 2$-dibenzothiophenes $\left(\mathrm{C}_{2} \mathrm{D}\right)$, C3-dibenzothiophenes $\left(\mathrm{C}_{3} \mathrm{D}\right)$, chrysene $\left(\mathrm{C}_{0} \mathrm{C}\right)$, C1-chrysenes $\left({ }_{1} \mathrm{C}\right), \mathrm{C} 2$-chrysenes $\left(\mathrm{C}_{2} \mathrm{C}\right)$, C3-chrysenes $\left(\mathrm{C}_{3} \mathrm{C}\right)$ acenaphthylene (ACEN), acenaphthene (ACE), fluoranthene (FLUOR), pyrene (PYR), and C1-pyrene/fluoranthene (C1-PYR/FLUOR).

Alkanes quantitated include: decane (C10), undecane (C11), tridecane (C13), tetradecane (C14), pentadecane (C15), hexadecane (C16), heptadecane (C17), pristine (Pri), octadecane (C18), n-eicosane (C20), docosane (C22), n-tetracosane (C24), nhexacosane (C26), n-octacosane (C28), n-triacontane (C30), n-dotriacontane (C32), and nhexatriacontane (C36). C30-Hopane was also quantified. (Urbano et al., 2013a). QA/QC included blanks, continuing calibration check samples and calibration using internal standards when necessary.

\subsubsection{Weathering ratios}

Ratios of more readily biodegradable oil components to more persistent components were used to determine weathering trends at field sites over time. Target compounds were normalized and compared to the sum of the persistent alkylated, 4-ring chysenes using equation 2.4.

$$
W R=\frac{100 * x}{x+\Sigma C_{n} C}
$$


Equation 2.4 is used to define the weathering ratios of targeted compounds, where WR = weathering ratio, $\mathrm{x}=$ target compound (i.e., $\mathrm{C}_{1} \mathrm{P}$ ) or target alkylated $\mathrm{PAH}$ group (i.e., $\Sigma \mathrm{C}_{n} \mathrm{P}$ ), and $\Sigma \mathrm{C}_{n} \mathrm{C}$ is the sum of the alkylated chrysenes $\left(\mathrm{C}_{1} \mathrm{C}+\mathrm{C}_{2} \mathrm{C}+\mathrm{C}_{3} \mathrm{C}\right)$. The parent PAHs (i.e. $\mathrm{C}_{0} \mathrm{~N}$, $\mathrm{C}_{0} \mathrm{~F}, \mathrm{C}_{0} \mathrm{P}, \mathrm{C}_{0} \mathrm{D}$, and $\mathrm{C}_{0} \mathrm{C}$ ) were present at low concentrations and in some cases below the detection limit.

\subsubsection{Statistical Analysis}

Statistical analysis was performed using a two-tailed student t-test at a 95\% confidence interval.

\subsection{Results and Discussion}

\subsubsection{Weathering of PAHs and alkanes}

Weathering ratios are presented for the Fourchon marsh site over a 26-month period (Figure 2.2). In samples collected on 08/11/11 $(n=5)$ and 11/07/13 (n=4), alkylated phenanthrenes, dibenzothiophenes and chrysenes account for the highest percentage of remaining, quantified PAHs, which is consistent with weathered MC252 oil from other sites (Liu et al., 2012). Figure 2.2 (A) shows a significant decrease in the $\mathrm{C}_{4} \mathrm{~N}(\mathrm{p}=0.025), \mathrm{C}_{1} \mathrm{P}$ $(p=0.016), C_{2} P(p=0.004), C_{1} D(p=0.025), C_{1} F(p=0.016)$, and total $P A H$ ratios $(p=0.016)$ from the August 2011 sample to the November 2013 samples. The more alkylated 3-ring compounds $\mathrm{C}_{3} \mathrm{P}, \mathrm{C}_{4} \mathrm{P}, \mathrm{C}_{2} \mathrm{D}, \mathrm{C}_{3} \mathrm{D}$ and the alkylated 4-ring compounds $\mathrm{C}_{1} \mathrm{C}, \mathrm{C}_{2} \mathrm{C}$, and $\mathrm{C}_{3} \mathrm{C}$ show no significant decrease $(\mathrm{p}<0.05)$ over the 26 months of sampling at the marsh site. The data is consistent with expected biodegradation trends, namely the decrease in rates as alkylation and number of aromatic rings increases (Cerniglia, 1993; Wang et al., 1998). 

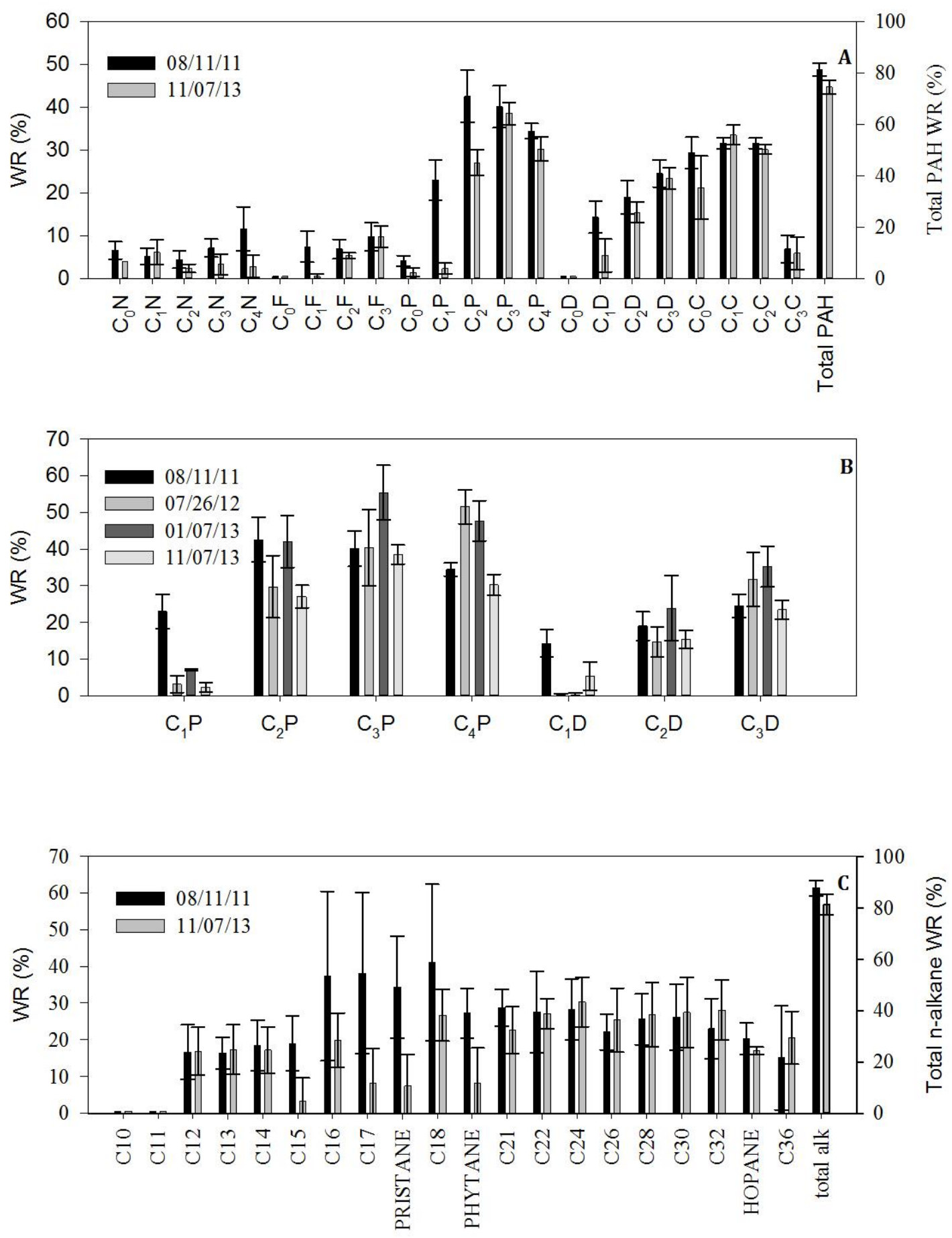

Figure 2.2. Weathering ratios of PAHs and n-alkanes in Fourchon Marsh 
Changes in weathering ratios constructed to examine individual alkylated phenanthrenes weathering relative to the chrysenes were examined on four different sampling dates: 08/11/11 (n=5), 07/26/12 (n=4), 01/07/13 (n=4), and 11/07/13 (n=4) [Figure 2.2 (B)]. $\mathrm{C}_{1} \mathrm{P}$ decreased by an order of magnitude from November 2011 to July 2012, relative to the alkylated chrysenes. The $\mathrm{C}_{1} \mathrm{P}$ ratio remained low in all subsequent samples at the marsh site. There was a significant decrease in $\mathrm{C}_{2} \mathrm{P}$ over the course of all samples; however, the intermediate samples do not show a consistent trend of weathering. $\mathrm{C}_{3} \mathrm{P}$ and $\mathrm{C}_{4} \mathrm{P}$ indices show no decrease in the concentrations between the first and last samples. Intermediate samples show higher concentrations of the compounds relative to the chrysenes, which may reflect site variability. Dibenzothiophenes followed a similar weathering pattern as phenanthrenes. The less alkylated $\mathrm{C}_{1} \mathrm{D}$ shows weathering in the first year of sampling and the more alkylated $\mathrm{C}_{2} \mathrm{D}$ and $\mathrm{C}_{3} \mathrm{D}$ persist.

There was no statistically significant decrease in n-alkane weathering ratios in these samples over the 27 months of the experiment [Figure $2.2(\mathrm{C})$ ]. This lack of weathering may be explained by the relatively low concentrations of $n$-alkanes at the start of the study. Remaining alkanes may be trapped in zones unfavorable for weathering processes.

Weathering ratios from the Fourchon beach marsh and mangrove sites were compared with those computed from the Bay Jimmy marsh, oil taken from the surface near the wellhead in 2010 and pieces of submerged oil mats (SOMs) collected after TS Lee in Fall 2011 (Table 2.1). Samples showed varying degrees of weathering. When arranged chronologically, weathering ratios indicate that oil present in the Fourchon Beach marsh site had undergone significantly more weathering than oil at the nearby Fourchon Beach mangrove site in August of 2011. There is a significant difference in $\mathrm{Cnn}_{n}(\mathrm{p}<0.001), \mathrm{Cn}_{n} \mathrm{~F}$ 
Table 2.1. Analysis of PAH and n-alkane ratios from various samples

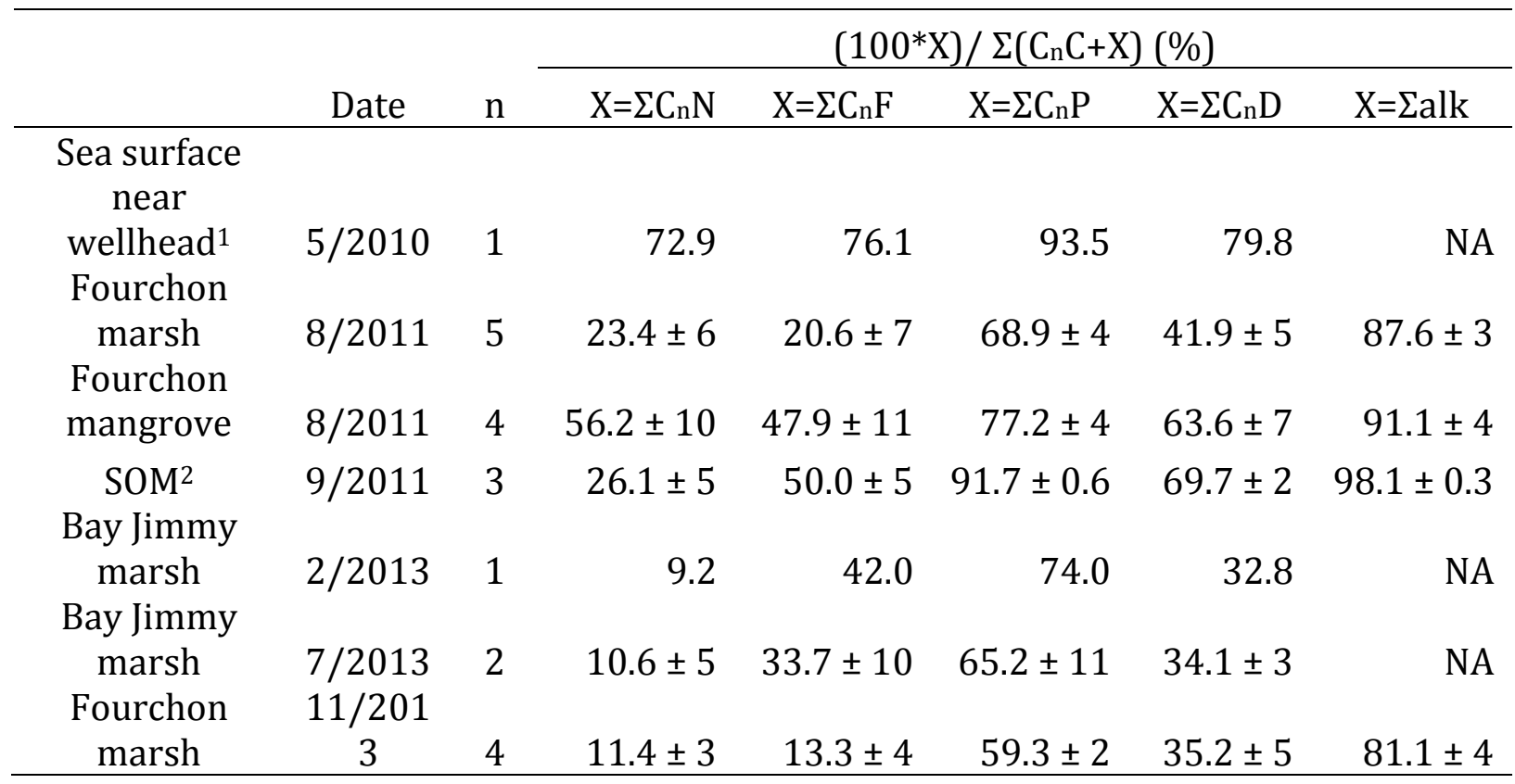

${ }^{1}$ Site 30 from surface (Diercks et al., 2010), ${ }^{2}$ Collected from Fourchon Beach on $09 / 16 / 2011$

( $\mathrm{p}=0.003), \mathrm{C}_{\mathrm{n}} \mathrm{P}(\mathrm{p}=0.019)$, and $\mathrm{C}_{\mathrm{n}} \mathrm{D}(\mathrm{p}<0.001)$ relative to alkylated chrysenes between the 2 locations at that date. Since the date of oiling of these 2 sites is known exactly (week of $5 / 20 / 2010$ ), differences in the weathering ratios reflect real differences in processes occurring at the two sites, separated by only 50 meters. The most obvious difference is the mangrove site sediments are typically below the low tide while the oiled marsh sediments are above.

The SOM samples and the data collected from near the wellhead (Diercks et al., 2010) place bounds on the weathering ratios for comparison with the samples from the wetlands. SOMs are typically completely submerged and oxygen limitations can be hypothesized to cause PAH persistence in these samples (Urbano et al., 2013a). Using the wellhead and SOM samples as a reference, naphthalenes continued to weather relative to chrysenes and by 2013, Fourchon marsh and Bay Jimmy marshes had similar weathering ratios. Fluorene 
weathering was also noted in Fourchon marsh samples at a similar rate to the naphthalenes but notably slower in the Bay Jimmy samples. Loss of phenanthrenes was slower and in the Fourchon marsh, weathering is occurring at a rate of 5\% per year. Dibenzothiophenes were weathering at a similar rate, approximately $5 \%$ per year. While limited Bay Jimmy samples are available, there was no noticeable difference in weathering ratios for samples collected in February and July of 2013. Finally, the weathering of alkanes in the Fourchon marsh and mangrove was substantially slower than many of the PAHs, in contrast with previous studies showing more rapid alkane loss over PAHs.

\subsection{2 $\delta^{13} \mathrm{C}-\mathrm{CO}_{2}$ flux}

To determine whether the observed weathering was due to biodegradation, mineralization assays using stable isotopic measurements on evolved $\mathrm{CO}_{2}$ were conducted. The $\delta^{13} \mathrm{C}$ signature of MC252 oil ( $\left.\mathrm{S}_{0}\right)$ has been reported as $-27 \pm 0.2 \%$ (Natter et al., 2012). The indigenous organic matter $\delta^{13} \mathrm{C}$ signature $\left(\mathrm{S}_{\mathrm{i}}\right)$ at each marsh location was determined to be $-16.98 \%$ and $-15 \%$ for the Port Fourchon and Bay Jimmy site, respectively (Table 2.2). The measured $\delta^{13} \mathrm{C}$ signature of the produced $\mathrm{CO}_{2}\left(\mathrm{~S}_{\mathrm{t}}\right)$ from the flux chambers ranged from -16.8 to $20.2 \%$ across all four sampling events (Table 2.2). These signatures are more negative than the background signatures suggesting a portion of the $\mathrm{CO}_{2}$ originated from a source more depleted in ${ }^{13} \mathrm{C}$ than the indigenous organic matter. This ignores, at present, the discrimination of ${ }^{13} \mathrm{C}$ over ${ }^{12} \mathrm{C}$ that could occur in any transport or fate process like biodegradation (Griebler et al., 2003) . When the sources are separated using Eq. 2.2 and 2.3, $\mathrm{CO}_{2}$ flux from crude oil mineralization ranged from 2.9-12.1 $\mathrm{mg} \mathrm{CO}_{2}-\mathrm{C} \mathrm{m}^{-2} \mathrm{hr}^{-1}$ at the two locations. These compare favorably to previous measurements of crude oil derived $\mathrm{CO}_{2}$ flux determined by this technique in marshes near Fourchon Beach (Jackson et al., 1996). 
Table 2.2. $\delta^{13} \mathrm{C}$ signatures and source-apportioned mineralization rates from the field

\begin{tabular}{|c|c|c|c|}
\hline Sample & $\delta^{13} \mathrm{C}(\%)$ & $\begin{array}{l}\mathrm{CO}_{2} \text { from crude oil } \\
\text { mineralization } \\
\left(\mathrm{mg} \mathrm{CO}-\mathrm{C} / \mathrm{m}^{2 *} \mathrm{hr}\right)\end{array}$ & $\begin{array}{c}\mathrm{CO}_{2} \text { from } \\
\text { indigenous } \\
\text { carbon } \\
\text { mineralization } \\
\left(\mathrm{mg} \mathrm{CO}_{2-}\right. \\
\left.\mathrm{C} / \mathrm{m}^{2 *} \mathrm{hr}\right) \\
\end{array}$ \\
\hline Fourchon shoreline winter a & $-17.6 \pm 0.8$ & $2.9 \pm 3.9$ & $58.7 \pm 25.4$ \\
\hline Fourchon shoreline summer a & $-18.3 \pm 1.1$ & $2.7 \pm 2.3$ & $18.1 \pm 2.9$ \\
\hline Bay Jimmy shoreline winter a & $-20.2 \pm 1.7$ & $12.1 \pm 4.1$ & $15.7 \pm 3.7$ \\
\hline Bay Jimmy shoreline summer b & -16.8 & 3.2 & 18.0 \\
\hline
\end{tabular}

The winter sampling of Bay Jimmy shoreline showed over 3 times more oil derived $\mathrm{CO}_{2}$ than any of the other samples. The Bay Jimmy shoreline location was determined to be the most heavily oiled location ( $>80 \mu \mathrm{g}$ PAHs / g of soil in the top $5 \mathrm{~cm}$ ) by cores taken adjacent to each flux chamber (Figure 2.3). Figure 2.3 also shows that oiling at both locations was minimal at depths below $10 \mathrm{~cm}$. Evolved $\mathrm{CO}_{2}$ production from indigenous organic matter ranged from 58.7- $15.7 \mathrm{mg} \mathrm{CO}_{2}-\mathrm{C} \mathrm{m}^{-2} \mathrm{hr}^{-1}$ at the two locations. The Fourchon marsh shoreline winter sample produced the most $\mathrm{CO}_{2}$ of all the samples with $96 \%$ of the $\mathrm{CO}_{2}$ being evolved from organic matter. Differences in summer and winter $\mathrm{CO}_{2}$ evolution is complicated by tidal conditions at the time of sampling. The $\delta^{13} \mathrm{C}$ signatures of the marsh soil at the Fourchon Beach and Bay Jimmy marshes were measured to assess whether the evolved $\mathrm{CO}_{2}$ signature reflected the existing signature in the bulk soil. These measurements are depicted in Figure 2.4 for the total bulk soil (A, D), soil separated from the roots $(\mathrm{B}, \mathrm{E})$, and the roots alone $(\mathrm{C}, \mathrm{F})$ in homogenized $5 \mathrm{~cm}$ core sections to a depth of $25 \mathrm{~cm}$. The $\delta^{13} \mathrm{C}$ signatures of the individual samples are separated into two groups: before and after extraction using a 50:50 mixture of hexane and acetone, designed to remove oil 

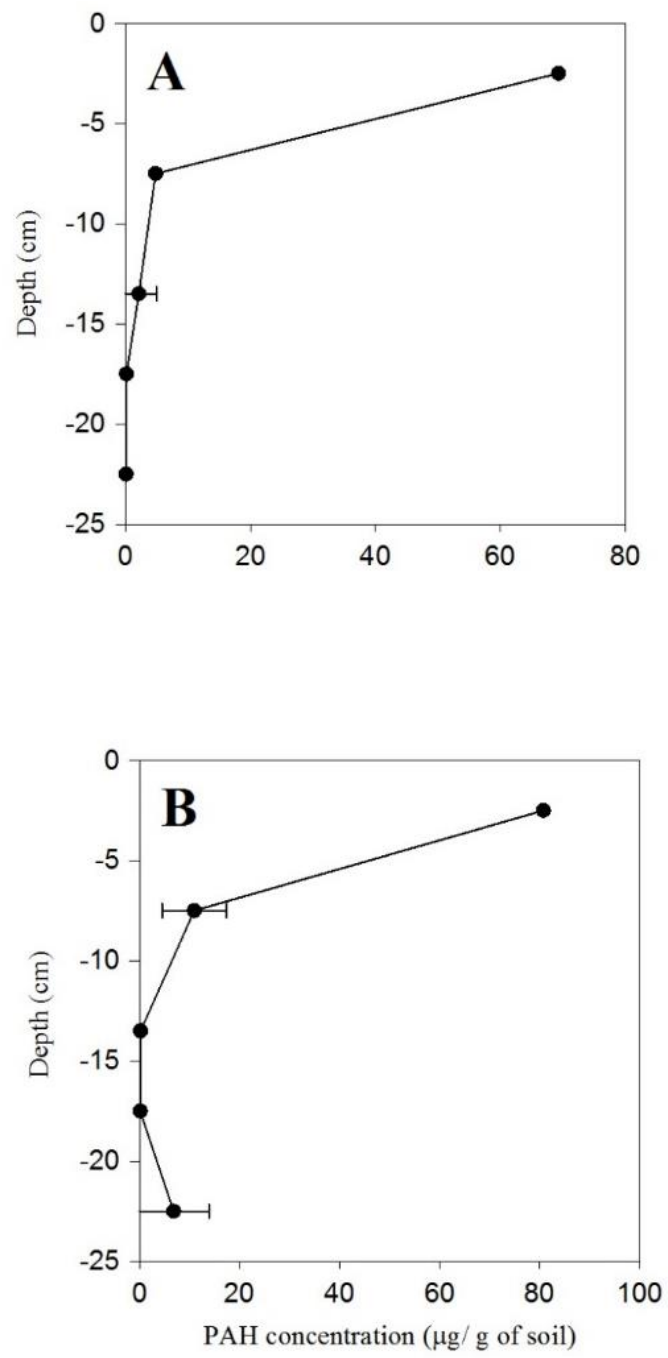

Figure 2.3. PAH concentration at depth in shoreline cores at (a) Fourchon beach and (b)Bay Jimmy

from the sample. For every measurement in the top $5 \mathrm{~cm}$ of the core the signature increased after the extraction process, which signifies the removal of ${ }^{13} \mathrm{C}$-depleted crude oil. In the top $5 \mathrm{~cm}$ sections of the Fourchon [Figure 2.4(A)] and Bay Jimmy [Figure 2.4 (D)] cores the total signature increased from $-24.9 \pm 0.8 \%$ o to $-21.5 \pm 0.9 \%$ and from -25.9 $\pm 1.2 \%$ o to $-21.1 \pm 0.4 \%$, respectively, after extraction. Figure 2.4 confirms that oil is altering the $\delta^{13} \mathrm{C}$ signature of the marsh soils. 
$\multimap$ Unextracted $\multimap-$ Hex:Ace Extracted
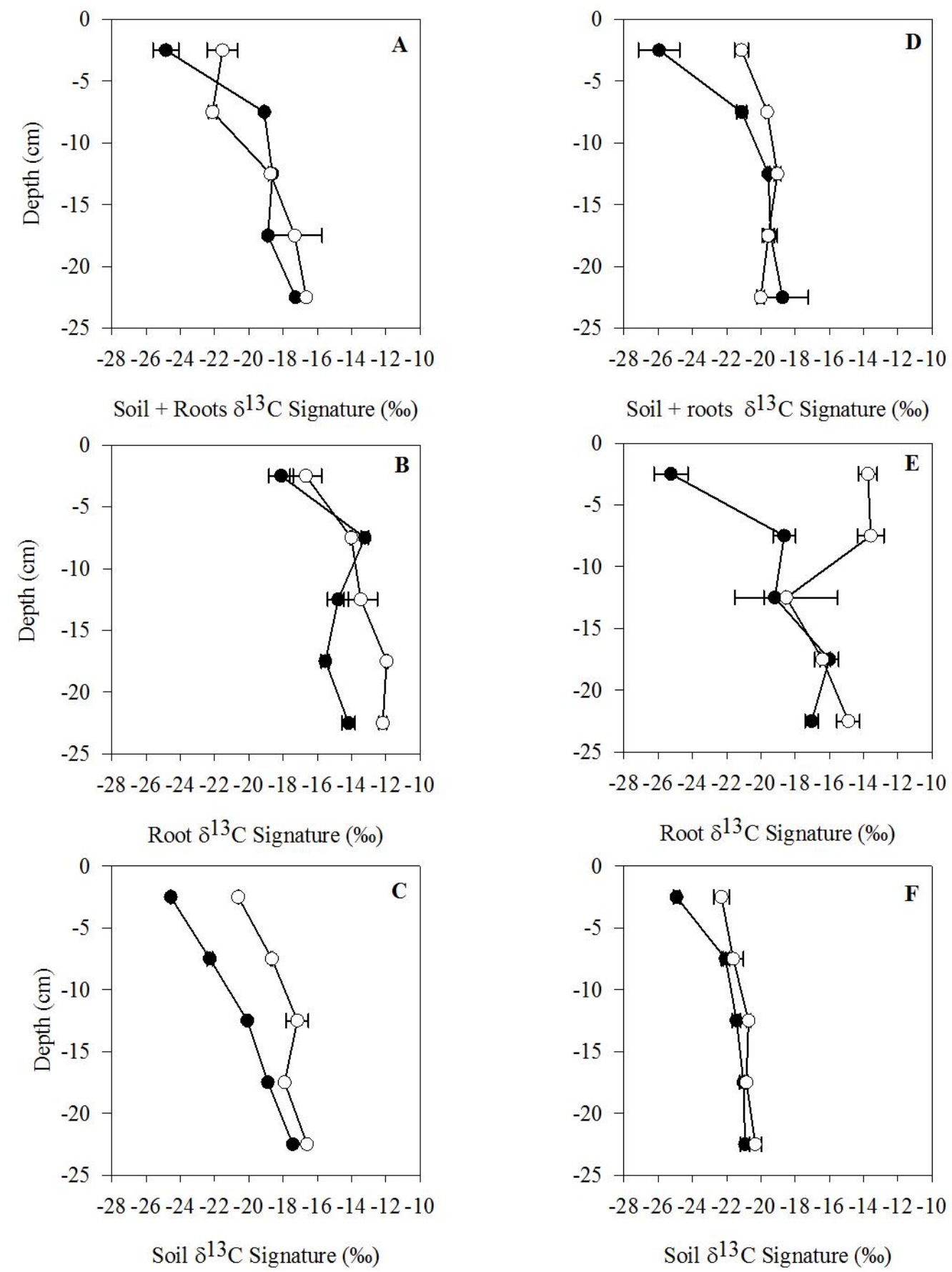

Figure 2.4. $\delta^{13} \mathrm{C}$ signatures of bulk soil $(\mathrm{A}, \mathrm{D})$, root matter with soil removed $(\mathrm{B}, \mathrm{E})$ and soil with roots removed (C,F) for $5 \mathrm{~cm}$-core sections from the Fourchon beach marsh site shoreline $(A, B, C)$ and the Bay Jimmy site shoreline $(D, E, F)$. 
The measured $\delta^{13} \mathrm{C}$ signatures from $\mathrm{CO}_{2}$ evolution were different than the signature of the bulk soil. If the signature of the evolved $\mathrm{CO}_{2}$ is derived from either organic matter source (marsh organic matter and crude oil), the $\delta^{13} \mathrm{C}$ signature from the $\mathrm{CO}_{2}$ flux chambers should equal the signature of the bulk soil. Again, this ignores the discrimination of ${ }^{13} \mathrm{C}$ over ${ }^{12} \mathrm{C}$ that could occur in any transport or fate process like biodegradation (Griebler et al., 2003) . In each sample of evolved CO2, the signature is larger (less negative) than expected from the value in the bulk soil. This suggests that the natural organic matter is being mineralized preferentially over the crude oil components, as expected, but mineralization via aerobic or anaerobic is occurring at a rate and extent to continue to alter the evolved $\delta^{13} \mathrm{C}$ signatures as long as 3 years after the spill event. Based on this, at least a portion of the observed weathering is from biodegradation as reflected by the mineralization observed here.

Hydrocarbon mineralization rates range from 2.7 to $12.1 \mathrm{mg} \mathrm{CO}_{2}-\mathrm{C} \mathrm{m}^{-2} \mathrm{hr}^{-1}$. This mineralization occurs within the marsh soil to an indefinite depth. Hydrocarbon mineralization rates in this range from 2.7 to $12.1 \mathrm{mg} \mathrm{CO}_{2}-\mathrm{C} \mathrm{m}^{-2} \mathrm{hr}^{-1}$. By taking a theoretical $1 \mathrm{~m}$ x $1 \mathrm{~m}$ area of marsh and assuming a $10 \mathrm{~cm}$ oiling depth, a $1.5 \mathrm{~kg}$ soil $/ \mathrm{cm}^{3}$ marsh bulk density, $0.1 \%(\mathrm{~m} / \mathrm{m})$ of oil to soil, and a carbon composition of oil to be $88 \%$ $(\mathrm{m} / \mathrm{m})$ a total of $13,200 \mathrm{~g}-\mathrm{C} \mathrm{m}^{-2}$ marsh was calculated. The crude oil mineralization rates recorded in Table 2.2 would account for a $0.2-0.8 \%$ reduction. Depending on tide and temperature among other environmental factors impacting mineralization, these rates may vary greatly at different times. According to weathering patterns described above, weathering of certain MC252 oil components was taking place at an approximate rate of 
$5 \%$ per year.. This indicates that mineralization of hydrocarbons is taking place at a rate comparable to field weathering rates.

\subsubsection{Nutrient and electron acceptor profiles}

Marsh and mangrove dialysis samplers in Fourchon Beach wetlands generated porewater depth profiles for sulfate, ammonium, and phosphorous (Figure 2.5). Locations $4 \mathrm{~A}$ and $5 \mathrm{~A}$ at the Fourchon marsh site and 1D and 2D at the Fourchon mangrove site were determined by the grab samples to be the most heavily contaminated by MC252 oil. Figure 2.5 (A) and 2.5 (D) show sulfate concentrations in the top $50 \mathrm{~cm}$ of the marsh profile were maintained at $>1,000 \mathrm{mg} / \mathrm{L}$. These concentrations are replenished by daily tidal action from the adjacent bay. Among the 8 dialysis samplers at this site,, four locations ( $5 \mathrm{~A}$ winter, 4A summer, 5A summer, and 1D summer) showed sulfate depletion (concentrations $<500$ $\mathrm{mg} \mathrm{SO} 4^{2-} / \mathrm{L}$ ) at a depth within the top $20 \mathrm{~cm}$. At depths below the areas of sulfate depletion, the sulfate concentrations returned to concentrations higher than $1000 \mathrm{mg} / \mathrm{L}$. Lower sulfate concentrations may be attributed to sulfate reduction coupled with hydrocarbon degradation, which has been observed previously in these Louisiana salt marsh systems (Shin et al., 2000). Sulfate is expected to be more depleted during summer months when temperatures are high and reaction kinetics are faster. Summer sampling shows sulfate depletion in 3 of the 4 summer samples and winter sampling accounts for 1 sampler showing sulfate depletion out of 4. Plots in Figures 2.5 (B), 2.5 (C), 2.5 (E) and 2.5 (F) show that in all dialysis samplers that exhibited sulfate depletion in the top $20 \mathrm{~cm}(5 \mathrm{~A}$ winter, $4 \mathrm{~A}$ summer, $5 \mathrm{~A}$ summer, and $1 \mathrm{D}$ summer), a corresponding increase in ammonium and/or phosphorous was observed. These increases in porewater nutrient concentrations likely reflect zones of intense anaerobiosis that leads to dissolution of iron oxyhydroxides 

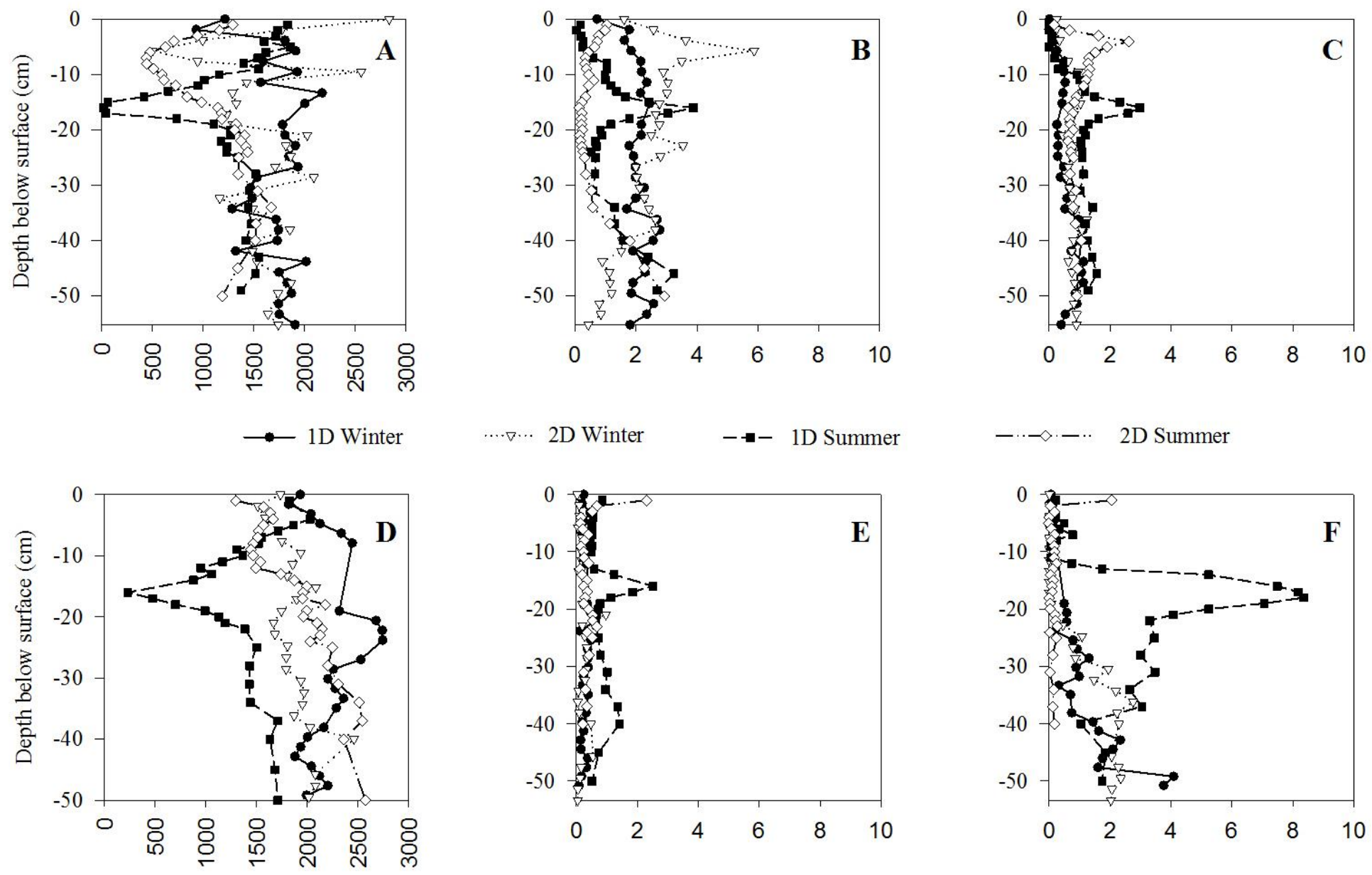

$\cdot \nabla \cdots 2$ D Winter

$-\rightarrow-$ 1D Summer

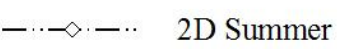

Sulfate concentration $(\mathrm{mg} / \mathrm{L})$
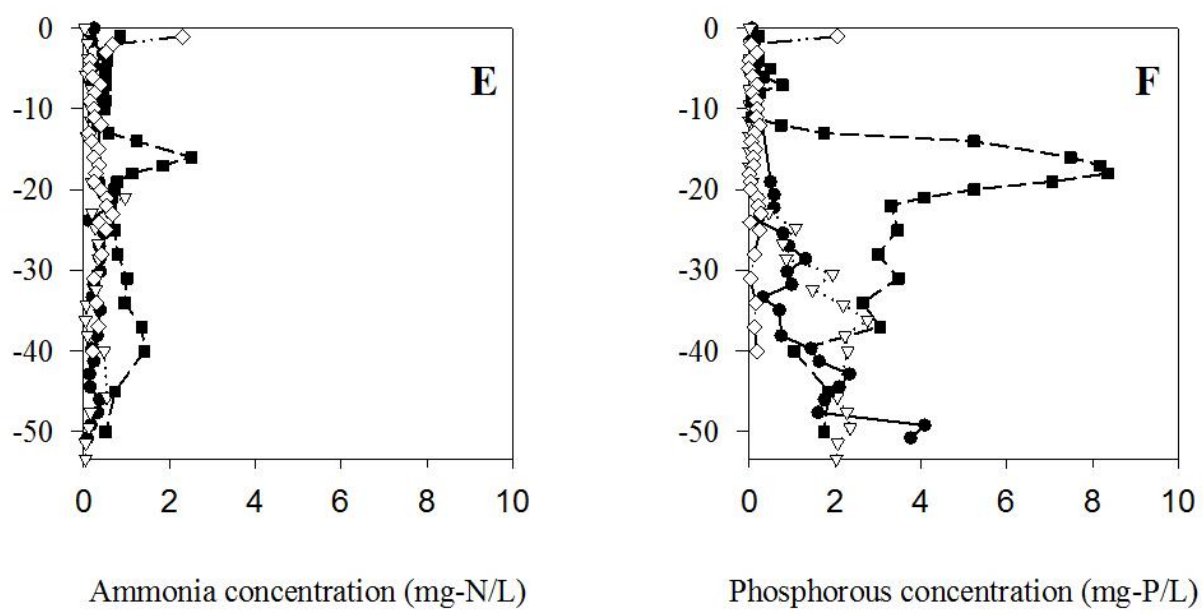

Figure 2.5. Seasonal pore water sulfate $(\mathrm{A}, \mathrm{D})$, ammonium $(\mathrm{B}, \mathrm{E})$, and phosphorous $(\mathrm{C}, \mathrm{F})$ concentrations at different depths at locations $4 \mathrm{~A}$ and $5 \mathrm{~A}$ at the Fourchon beach marsh site and locations 1D and 2D at the Fourchon beach mangrove site. 
resulting in P release. Net ammonium release would also occur as the high C:N ratio of the oil substrate exceeds that of the microbial population degrading the oil. With the exception of the depths that show increased nutrient concentrations coupled with sulfate reduction, ammonia and phosphorous concentration remain relatively constant throughout the profile with the marsh site having slightly higher porewater nutrients concentrations than the mangrove site.

Figure 2.6 shows nutrient and potential electron acceptor porewater profiles at 4 shoreline locations at the Bay Jimmy site. Data is presented from 2 shoreline segments (A and E). Locations A3 and A5 are located in a heavily oiled section of the shoreline used for the $\delta^{13} \mathrm{C}-\mathrm{CO}_{2}$ and weathering indices data above. Shoreline locations E3 and E5 are approximately 100 yards southeast of A3 and A5 and while oiled, have lower concentrations in the top $15 \mathrm{~cm}$ of the marsh surface than segment A (data not shown). Figure 2.6 (A) and 2.6 (D) shows that sulfate concentrations at the Bay Jimmy site are lower than the Fourchon beach sites as expected due to their position in the estuary. The sulfate, ammonium, and phosphorous profile trends in segment A contrast greatly with those of segment E. In the A plots [Figure 2.6 (A)], sulfate concentration was very low $(<200 \mathrm{mg}$ $\mathrm{SO}_{4}^{2-} / \mathrm{L}$ ) at depths below $20 \mathrm{~cm}$ for all samples excluding the $\mathrm{A} 5$ summer sample. In the $\mathrm{E}$ plots [Figure 2.6(D)], sulfate varies over a much wider range and depletion of sulfate with depth is much less common. These depleted zones of sulfate in the Bay Jimmy A segment are similar to the areas of the Fourchon Beach marsh and mangrove profiles and may represent demand for sulfate from hydrocarbon-linked sulfate reduction that exceeds supply in these systems. 

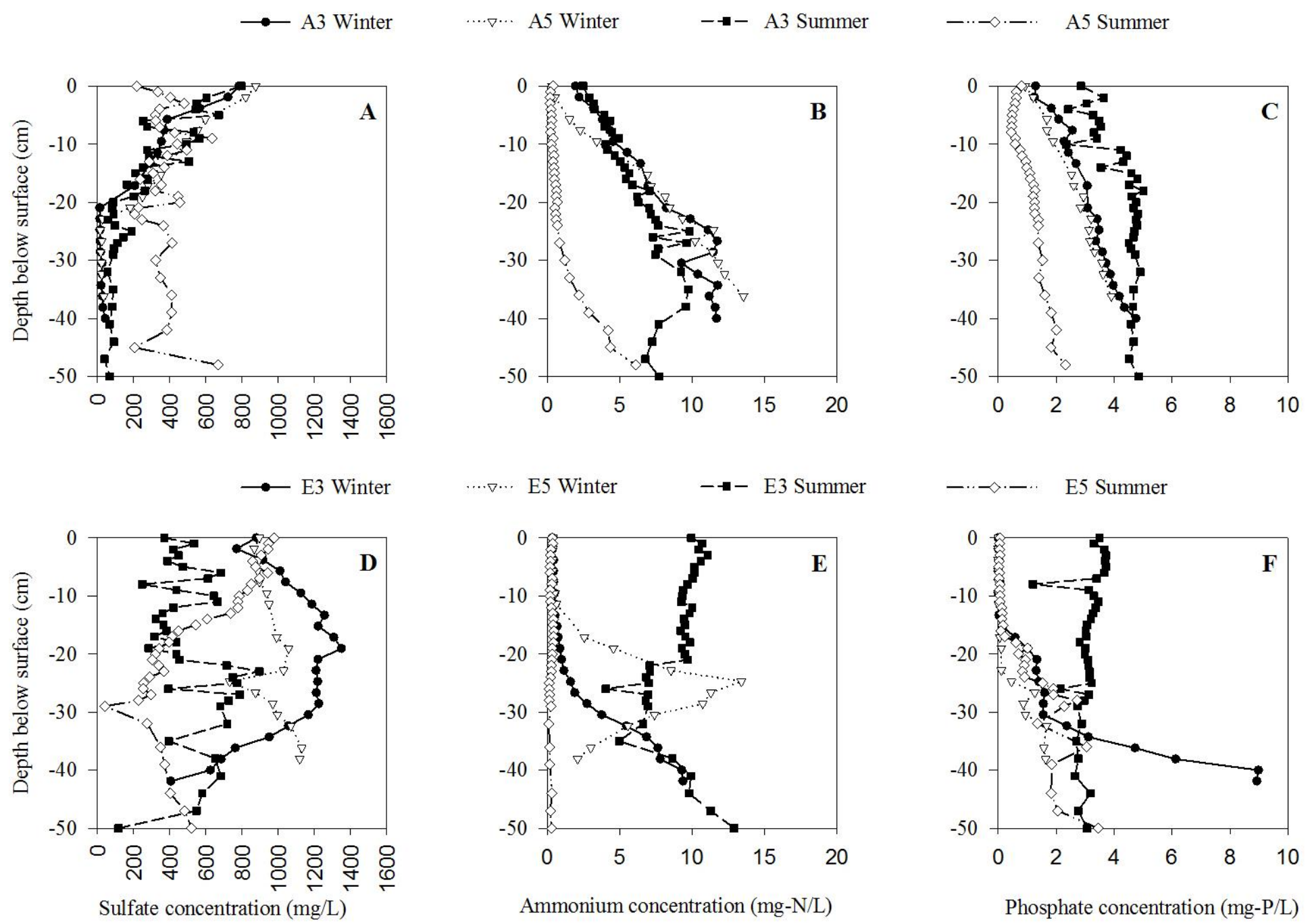

Figure 2.6. Seasonal pore water sulfate $(\mathrm{A}, \mathrm{D})$, ammonium $(\mathrm{B}, \mathrm{E})$, and phosphorous $(\mathrm{C}, \mathrm{F})$ concentrations at different depths at locations A3, A5, E3, and E5 at the Bay Jimmy site 
Nutrient concentrations in the Bay Jimmy plots reveal several trends. First, porewater ammonium and phosphorous concentrations were elevated in the top $20 \mathrm{~cm}$ of the marsh for the more heavily oiled Bay Jimmy segment. These mirror elevated $\mathrm{N}$ and P porewater concentrations observed in the sulfate-depleted zones of the Fourchon profiles. Zones of anaerobiosis in the Bay Jimmy samples may explain these nutrient release patterns. A second trend was the very low $\mathrm{N}$ and $\mathrm{P}$ concentrations observed in the top $20 \mathrm{~cm}$ of 3 of the 4 samples taken from the $\mathrm{E}$ segment. The difference in the two segments may be a difference in elevation of the samplers. The shoreline is rapidly eroding across this entire shoreline, and dialysis samplers along the E segment were placed at a higher elevation to avoid having them in the open waters of Barataria Bay. These samplers were stranded above regular tidal inundation when compared with the samplers from segment $\mathrm{A}$, which may explain why lower nutrient concentrations were observed at this location. The implications for oiled marsh segments at these higher elevations are unknown but nutrient availably from marsh porewater may be a trade-off with higher oxygen penetration into the bed.

\subsection{Conclusion}

Weathering of MC252 PAHs and n-alkane is occurring in these marsh and mangrove wetlands. The weathering rates increase as the molecular weights and ring structure of thcomponents decrease. Increased alkylation of compounds also contributes to decreased weathering rates. At the Fourchon cite, weathering rates at the marsh locations were faster than the nearby mangrove location. $\mathrm{C}_{\mathrm{n}} \mathrm{P}$ and $\mathrm{C}_{\mathrm{n}} \mathrm{D}$ accounted for the largest percentage of PAHs in marsh and mangrove contaminated soils. Weathering of these compounds relative 
to alkylated chrysenes is taking place at an approximate rate of 5\% per year. Oiling in field samples was limited to the top $10 \mathrm{~cm}$ of soil in most cases.

Biodegradation can account for a portion of the weathering observed in the contaminated marsh and mangrove soils. $\delta^{13} \mathrm{C}$ signatures of evolved $\mathrm{CO}_{2}$-C are more negative than that of the indigenous organic matter. Lower $\delta^{13} \mathrm{C}$ signatures of evolved $\mathrm{CO}_{2}$ indicate mineralization of a carbon source more depleted in ${ }^{13} \mathrm{C}$ (hydrocarbons). This mineralization can only take place through biological processes. $\mathrm{CO}_{2}$ flux chambers collected hydrocarbon derived $\mathrm{CO}_{2}$ at a rate comparable to the amount of carbon that was lost due to weathering at these locations.

Dialysis sampler results indicate that there is a presence of readily biodavailable nitrogen and phosphorus to be used in biodegradation processes as well as sulfate to be used as an electron acceptor in anaerobic zones within each location. In order for $1 \mathrm{~g}$ of hydrocarbons to converted to cell mass, $150 \mathrm{mg}$ of nitrogen and $30 \mathrm{mg}$ of phosphorous is needed (Venosa and Zhu, 2003). Sulfate depletion was observed at depth corresponding to oiling in Fourchon and Bay Jimmy locations. This sulfate depletion may be attributed to hydrocarbon biodegradation by sulfate reducing bacteria in anaerobic soils. Oxygen concentrations in coastal marsh and mangrove systems are low to non-existent during high tides; however, during low tide soils in the upper $10 \mathrm{~cm}$ may become aerobic. Due to the tidal nature of these systems, both aerobic and anaerobic processes can account for oil weathering.

Biodegradation is an important process in the removal of oil constituents from contaminated, coastal marsh and mangrove wetlands. These biodegradation processes are happening slow in these anaerobic systems. Molecular weight, ring structure, and levels of 
alkylation are important factors that govern the rates of individual MC252 components. This study focuses only on PAH and n-alkane weathering and ignores other components of MC252 oil which may be more readily biodegradable or more persistent in these marsh and mangrove systems. 


\section{CHAPTER 3: BIODEGRADATION POTENTIAL OF POLYCYCLIC AROMATIC HYDROCARBONS IN COASTAL WETLANDS UNDER DIFFERENT REDOX CONDITIONS}

\subsection{Introduction}

MC252 oil from the Deepwater Horizon oil spill began reaching the northern Gulf of Mexico shoreline by May of 2010. A portion of the released petroleum was carried by gulf currents to the coastal salt marsh systems of Louisiana as a water-in-oil emulsion. Since few mechanical remedial options exist for crude oil in these systems, the natural weathering reactions that impact crude oil components under these conditions are of great interest, specifically biodegradation. The polycyclic aromatic hydrocarbons (PAHs) have been the focus of multiple biodegradation studies under conditions relevant to understanding the fate of MC252 in marshes (Anderson, 2013; Chang et al., 2002; Coates et al., 1996; Coates et al., 1997; Horel et al., 2012; Jackson and Pardue, 1999b; Venosa and Zhu, 2003). Biodegradation of PAHs can be an important weathering and removal processes if environmental factors (i.e. PAH concentration, temperature, oxygen, nutrients, pH, salinity, etc.) are favorable (Bossert and Bartha, 1984; Foght and Westlake, 1987; Head and Swannell, 1999; Jackson and Pardue, 1999b; Venosa and Zhu, 2003).

PAH biodegradation processes in salt marshes are heavily dependent upon the redox status of the system. PAH biodegradation linked with oxygen as an electron acceptor is well-known (Heitkamp et al., 1988); however, the oxygen demand in a coastal salt marsh system is high due to respiration of organic matter and the oxidation of sulfide produced by sulfate-reducing bacteria under flooded conditions(Atlas, 1981; Rockne and Strand, 1998; Shin et al., 2001). Due to this oxygen deficit, a significant percentage of organic matter mineralization occurs via anaerobic pathways (Jørgensen et al., 1990). Since any available 
nitrate is likely to undergo denitrification, sulfate is most commonly used as the electron acceptor in organic matter reduction in coastal salt marshes.(Coates et al., 1996). Biodegradation of petroleum components including some low molecular weight PAHs have been shown in prior studies under sulfate-reducing conditions (Annweiler et al., 2000; Caldwell et al., 1998; Chen et al., 2013; Coates et al., 1996; Tate et al., 2012).

Biodegradation rates of PAHs are dependent on many factors including the number of aromatic rings, molecular weight, level of alkylation, and positioning of the alkyl groups (Chen et al., 2013; Wang et al., 1998). The rate of PAH degradation decreases as the molecular weight and number of aromatic rings increase (Wang et al., 1998). Likewise, the degradation rate decreases as alkylation increases. Within each PAH family, the magnitude of the degradation rates should follow the series $\mathrm{C} 0>\mathrm{C} 1>\mathrm{C} 2>\mathrm{C} 3>\mathrm{C} 4$ (Wang et al., 1998). Based on this knowledge, extent of biodegradation can be expressed by changes in weathering ratios of more readily-biodegradable, low molecular weight PAHs (i.e. C1- and C2-phenanthrenes) to more stable, higher molecular weight PAHs (i.e. C2 and C3 chrysenes). Nitrogen and phosphorous can become limiting nutrients in an oil contaminated salt marsh as cell mass increases with the addition of the new carbon source (Venosa and Zhu, 2003). Nutrient addition or biostimulation has shown to be an effective method for increasing oil degradation rates (Shin et al., 2001). There have been a number laboratory and field studies to investigating which types and concentrations of nutrients should be added for optimal performance (Jackson and Pardue, 1999b; Wrenn et al., 1994).

The goal of this study was to observe and confirm the biodegradation of PAHs, more specifically the dominant PAHs which reaches the shoreline after the Deepwater Horizon spill, the alkylated PAHs C1-, C2-, C3-, C4-phenanthrenes, C2-, C3-dibenzothiophenes and 
C1, C2-chrysenes, in both aerobic and anaerobic enrichment culture experiments. Sulfate, ammonium, and phosphorous concentrations were measured during each sampling event to insure they did not become rate limiting in the enrichment culture. The hypothesis tested was that the alkylated PAHs would not undergo biodegradation during the experiment in the absence of oxygen. Previous work in this thesis measured declining weathering ratios from field samples in marsh and mangrove systems indicating that slow weathering was occurring. Mineralization was observed, as determined by $\delta^{13} \mathrm{C}-\mathrm{CO}_{2}$ measurements, but data were not available under more controlled laboratory conditions that could shed light on the redox condition required for biodegradation of the emulsified oil.

\subsection{Materials and Methods}

\subsubsection{Sediment}

Sediments from three Louisiana coastal wetlands contaminated by MC252 oil were collected for laboratory enrichment cultures. The 3 sites include a marsh located on the southern border of Bay Jimmy approximately 12 miles WSW of Port Sulphur, LA, a marsh site just inland of Fourchon Beach, dominated by the marsh grass Spartina alterniflora, and a second site inland of Fourchon Beach dominated by the mangrove, Avicennia germinans. The contaminated locations were intermittently flooded by tidal fluctuation. A $15 \mathrm{~cm}$ diameter core was taken at each site and the top $15 \mathrm{~cm}$ of the core was used in the enrichment culture study described below. 


\subsubsection{Petroleum Source}

For the enrichment culture studies conducted using sediments from the Fourchon Beach location, the petroleum source was the oil present in the wetland sediment from the spill, supplemented with crude oil believed to be MC252 from a submerged oil mat collected from the beach on $09 / 16 / 2011$ at $29.1583^{\circ} \mathrm{N}, 90.1018^{\circ} \mathrm{W}$. For the Bay Jimmy anaerobic enrichment culture, the sediment was contaminated to a greater extent; therefore, an additional petroleum source was not used.

\subsubsection{Aerobic enrichment culture experiments}

The Fourchon marsh site and the Bay Jimmy marsh site were the focus of an aerobic enrichment culture experiment. Sediment and water from each respective site was added to a $1000 \mathrm{~mL}$ Erlenmeyer flask, which was continuously stirred and aerated. The top of each flask was capped with a rubber stopper equipped with glass tubing for air injection. An aquarium pump was used to aerate the soil-water mixture. For each of the 2 sites, 4 enrichment cultures were prepared; 3 natural attenuation and 1 microbially -inhibited cultures. To inhibit the microbial community, 5 grams of sodium azide was added to the cultures. Water from each respective site was added to the samples weekly to account for evaporation and nutrient consumption.

For the Fourchon aerobic experiments, 50 grams of sediment collected on 09/11/13 at $29^{\circ} 08^{\prime} 00.16^{\prime \prime} \mathrm{N}, 90^{\circ} 08^{\prime} 43.48^{\prime \prime} \mathrm{W}$ was added to a 50 gram subsample of the aforementioned petroleum source. Cultures were maintained for 120 days. For the Bay Jimmy aerobic experiments, 50 grams of sediment collected on $06 / 26 / 13$ was added to a 50 gram subsample of the aforementioned petroleum source. The experiment took place over 120 days. 


\subsubsection{Anaerobic enrichment cultures}

Anaerobic enrichment culture experiments were conducted for each of the 3 coastal wetland sites. Cultures were constructed from $30 \mathrm{~mL}$, clear, glass, serum bottles containing wetland sediments, site water, and a petroleum source, if necessary. The enrichment cultures were prepared in an anaerobic glove box with a gas mixture of $5 \% \mathrm{H}_{2}$ gas and $95 \%$ $\mathrm{N}_{2}$ gas, and sealed with a Teflon-lined rubber stopper, and crimped shut with aluminum crimp caps to avoid any influx of oxygen. Enrichment culture bottles were tumbled for the first three days of the experiment and manually shaken monthly thereafter. For all 3 sets of enrichment cultures, samples were subjected to 1 of 5 different treatments; natural attenuation, sulfate addition, nitrogen addition, sulfate and nitrogen addition, or a killed control treatment. No nutrients were added to natural attenuation initially; however, sulfate and nitrogen were spiked back to background concentrations when levels dropped. Sulfate amended samples were spiked to a pore water sulfate concentration in excess of 20 mM to assure sulfate-reducing conditions (Boopathy et al., 2012; Hasinger et al., 2012). Nitrogen amended samples were spiked to a pore water nitrogen concentration of $100 \mathrm{mg}$ $\mathrm{NH}_{4}{ }^{+}-\mathrm{N}$ which was deemed to be a critical concentration to enhance degradation in a prior

study (Shin et al., 2001). Nitrogen was added in the form of ammonium chloride in order to add nitrogen as a nutrient without the addition of an electron acceptor such as nitrate or nitrite. The treatment of sulfate and nitrogen addition was accomplished by adding sulfate in excess of $20 \mathrm{mM}$ and nitrogen to a concentration of $100 \mathrm{mg} \mathrm{NH} 4^{+}-\mathrm{N}$. Each killed control sample was injected with $0.5 \mathrm{~mL}$ of formaldehyde. Experiments were set up for each treatment to be analyzed in triplicates at 5 different time steps $(\mathrm{N}=15)$. 
For the 2 Fourchon anaerobic experiments (marsh and mangrove), approximately 10 grams of sediment, 10 grams of the aforementioned petroleum source, and $20 \mathrm{~mL}$ of water collected adjacent to the 2 sites were added to each enrichment culture sample. The experiments took place over 301 days. For the Bay Jimmy anaerobic experiment, 20 grams of sediment was added to $20 \mathrm{~mL}$ of water collected adjacent to the shoreline.

\subsubsection{PAH and n-alkane extraction and analysis}

At each sampling time step, enrichment culture soil underwent oil extraction followed by measurement of PAH and n-alkane concentrations. Anaerobic enrichment cultures were completely sacrificed in the analysis while aerobic samples were subsampled to provide for the continuation of the experiment. Samples were transferred to Teflon centrifuge tubes for extraction. The tubes were centrifuged at 10,000 RPM for 15 minutes. Water was removed from the tubes and put aside for nutrient analysis. The remaining sediment sample was mixed with sodium sulfate and magnesium sulfate to remove remaining moisture before extraction. Oil constituents were extracted from the sediment using a Dionex Accelerated Solvent Extractor 350 (Thermo Scientific) with a 50:50 mixture of hexane and acetone as the solvent. The extract volume was reduced to $10 \mathrm{~mL}$ using a RapidVac $\mathrm{N}_{2}$ Evaporation System (Labconco, USA). One $\mu \mathrm{l}$ of each sample was injected onto a Hewlett Packard 6890N gas chromatograph equipped with a HP series autosampler, DB 5 capillary column ( $30 \mathrm{~m} \times 0.25 \mathrm{~mm} \times 0.25 \mu \mathrm{m}$ film) and HP 5973 mass selective detector. Temperature program for analysis was as follows: injector set to $300^{\circ} \mathrm{C}$, detector set to $280^{\circ} \mathrm{C}$, oven temperature set to $45^{\circ} \mathrm{C}$ for $3 \mathrm{~min}$ then increased at $6^{\circ} \mathrm{C} / \mathrm{min}$ to $315^{\circ} \mathrm{C}$ and held for $15 \mathrm{~min}$. Helium $(5.7 \mathrm{~mL} / \mathrm{min})$ was used as the carrier gas. Quantification was performed in selected ion monitoring mode using internal standards. 
PAHs quantitated include: naphthalene $\left(\mathrm{C}_{0} \mathrm{~N}\right), \mathrm{C} 1$-naphthalenes $\left(\mathrm{C}_{1} \mathrm{~N}\right), \mathrm{C} 2$-naphthalenes $\left(\mathrm{C}_{2} \mathrm{~N}\right)$, C3-naphthalenes $\left(\mathrm{C}_{3} \mathrm{~N}\right)$, C4-naphthalenes $\left(\mathrm{C}_{4} \mathrm{~N}\right)$, fluorene $\left(\mathrm{C}_{0} \mathrm{~F}\right)$, C1-fluorenes $\left(\mathrm{C}_{1} \mathrm{~F}\right)$, C2-fluorenes $\left(\mathrm{C}_{2} \mathrm{~F}\right)$, C3-fluorenes $\left(\mathrm{C}_{3} \mathrm{~F}\right)$ phenanthrene $\left(\mathrm{C}_{0} \mathrm{P}\right)$, C1-phenanthrenes $\left(\mathrm{C}_{1} \mathrm{P}\right), \mathrm{C} 2$ -

phenanthrenes $\left(\mathrm{C}_{2} \mathrm{P}\right)$, C3-phenanthrenes $\left(\mathrm{C}_{3} \mathrm{P}\right)$, C4-phenanthrenes $\left(\mathrm{C}_{4} \mathrm{P}\right)$, dibenzothiophene $\left(\mathrm{C}_{0} \mathrm{D}\right)$, C1-dibenzothiophenes $\left(\mathrm{C}_{1} \mathrm{D}\right), \mathrm{C}$-dibenzothiophenes $\left(\mathrm{C}_{2} \mathrm{D}\right)$, C3-dibenzothiophenes $\left(C_{3} D\right)$, chrysene $\left(C_{0} C\right)$, C1-chrysenes $\left(C_{1} C\right)$, C2-chrysenes $\left(C_{2} C\right)$, and C3-chrysenes $\left(C_{3} C\right)$. Alkanes quantitated include: decane (C10), undecane (C11), tridecane (C13), tetradecane (C14), pentadecane (C15), hexadecane (C16), heptadecane (C17), pristine (PRIS), octadecane (C18), n-eicosane (C20), docosane (C22), n-tetracosane (C24), nhexacosane (C26), n-octacosane (C28), n-triacontane (C30), n-dotriacontane (C32), and nhexatriacontane (C36). C30-Hopane was also quantified. QA/QC included blanks, continuing calibration check samples and calibration using internal standards when necessary.

\subsubsection{Nutrient and electron acceptor analysis}

A SmartChem 170 Discrete Analyzer (Unity Scientific Inc.) was used to measure nitrate $\left(\mathrm{NO}_{3}^{-}\right)$, nitrite $\left(\mathrm{NO}_{2}{ }^{-}\right)$, orthophosphates $\left(\mathrm{PO}_{4}^{3-}\right)$, ammonium $\left(\mathrm{NH}_{4}^{+}\right)$, and sulfate $\left(\mathrm{SO}_{4}{ }^{2-}\right)$ concentrations at each time step in all studies using EPA methods \#353.2, 353.3, 365.1, 350.1 and 375.4, respectively. QA/QC included blanks and recalibration before every run.

\subsubsection{Weathering ratios}

Ratios of more readily biodegradable oil components to more persistent components were used to compare biodegradation trends within and across studies. Individual PAHs and n-alkanes were normalized to the stable biomarker C30-Hopane (Prince et al., 1994). 
In addition, weathering ratio comparing PAHs and alkanes to the sum of the persistent alkylated, 4-ring, chysenes were computed using eq. 3.1.

$$
W R=\frac{100 * x}{x+\Sigma C_{n} C} \quad \text { Eq. } 3.1
$$

\subsubsection{Statistical analysis and computation}

Statistical analysis was performed using a two-tailed student t-test at $95 \%$ confidence interval. First-order rate constants from PAH and n-alkane losses were calculated using non-linear regression of data pooled from each sample during each sampling event.

\subsection{Results and Discussion}

\subsubsection{Chemical Evidence of PAH and n-alkane degradation in aerobic enrichments}

The ratio of targeted PAHs and n-alkanes normalized to the stable biomarker C30hopane were used to track degradation in aerobic enrichment cultures over the course of 120 days. Figures 3.1 and 3.2 show the hopane ratio for 5 different alkylated PAH families along with the sum of the targeted n-alkanes for the Fourchon and Bay Jimmy experiments, respectively. A killed control sample was collected during each sampling period to monitor abiotic losses of oil components. After 120 days of aeration, n-alkanes, $C_{n} C, C_{n} D, C_{n} P, C_{n} F$, and $\mathrm{C}_{\mathrm{n}} \mathrm{N}$ concentrations relative to $\mathrm{C} 30$-hopane showed a total decrease of $77,47,90,87$, 93, and 96\%, respectively, in the Port Fourchon enrichment cultures (Figure 3.1). As expected, the lighter 2- and 3-ring PAHs $\mathrm{C}_{n} \mathrm{~N}, \mathrm{C}_{n} \mathrm{~F}, \mathrm{C}_{\mathrm{n}} \mathrm{P}$, and $\mathrm{C}_{n} \mathrm{D}$ underwent the largest reduction due to their low molecular weight. There was no significant difference in the hopane ratios of any of the PAH families in relation to the killed control enrichment cultures after 30 days. The concentrations of all groups were reduced during that time 

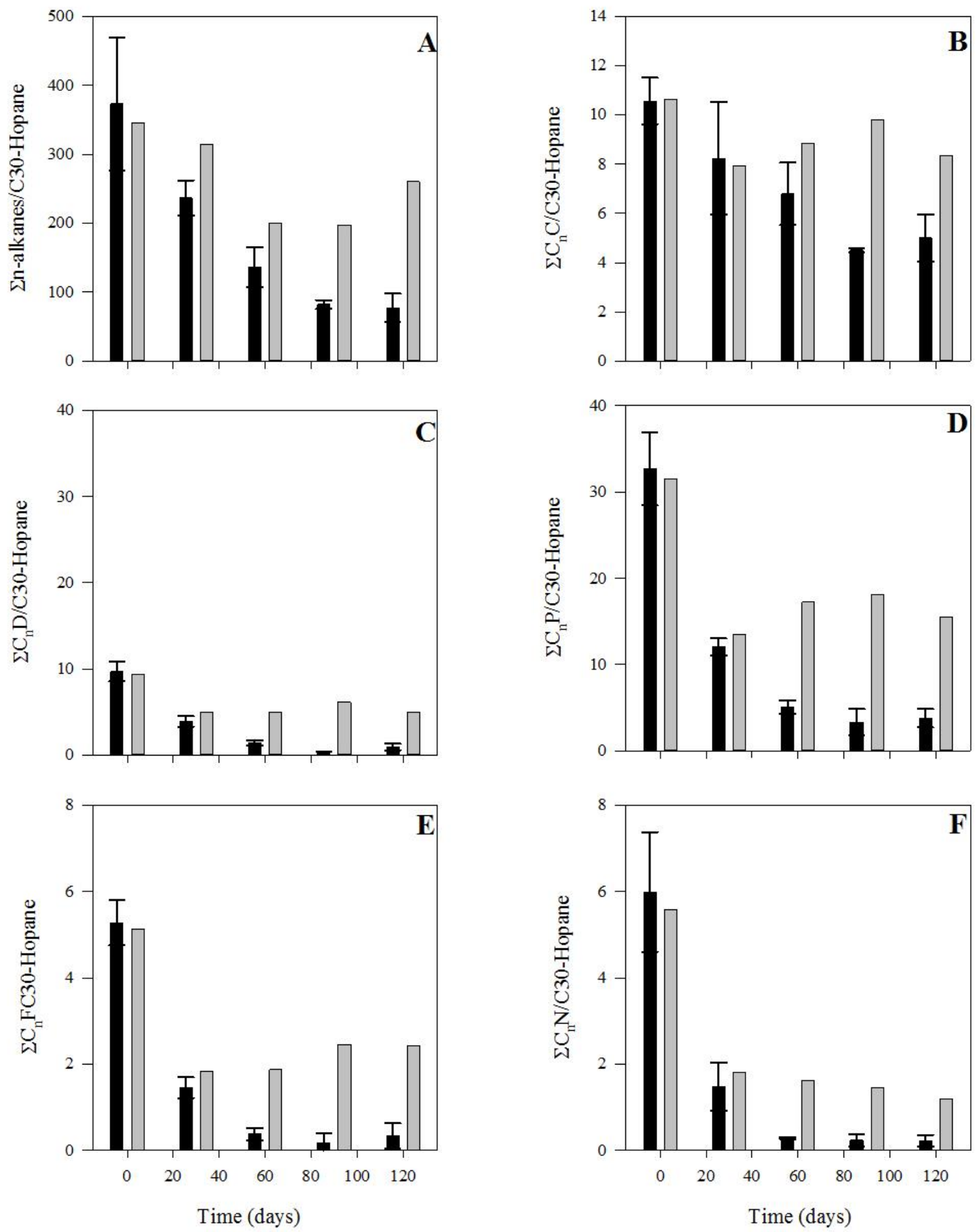

Figure 3.1. n-alkanes (A) and alkylated chysenes (B), dibenzothiophenes (C), phenanthrenes (D), fluorenes (E), and naphthalenes (F) relative to C30-hopane for aeratednatural attenuation and aerated-killed Fourchon marsh enrichment cultures 

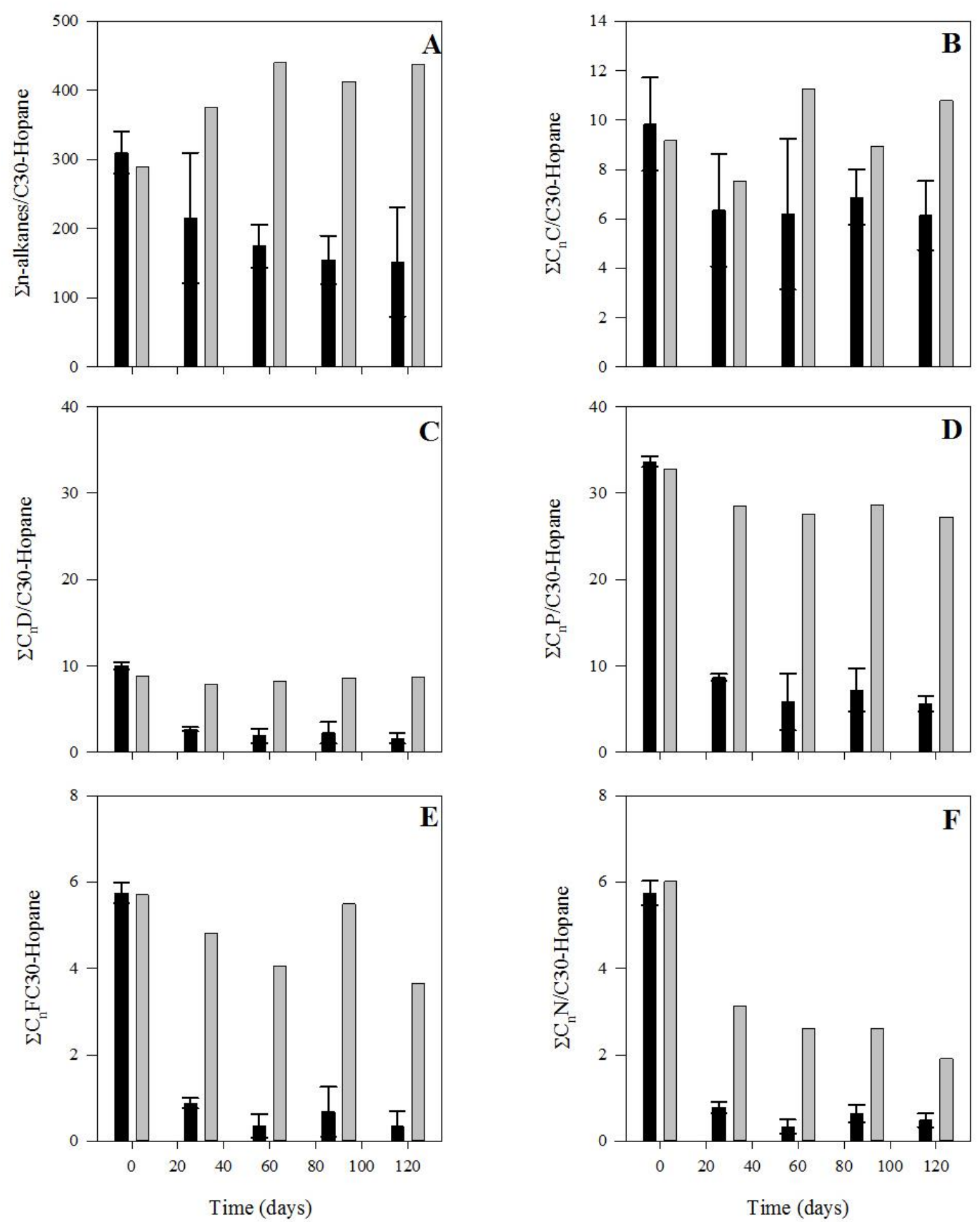

Figure 3.2. n-alkanes (A) and alkylated chysenes (B), dibenzothiophenes (C), phenanthrenes (D), fluorenes (E), and napthalenes (F) relative to C30-Hopane for Aeratednatural attenuation and aerated-killed Bay Jimmy marsh enrichment cultures 
span with $\mathrm{C}_{n} \mathrm{~N}, \mathrm{C}_{\mathrm{n}} \mathrm{F}$, and $\mathrm{C}_{\mathrm{n}} \mathrm{P}$ decreasing by $>50 \%$ for all killed and non-killed enrichment cultures. This can be attributed to the volatilization of a fraction the lighter components of each family expedited by the constant air inflow. After the initial drop in 30 days, killed control samples remained relatively constant while biodegradation processes further reduced alkylated PAH hopane ratios. After 60 days there is a significant difference in $\mathrm{C}_{n} \mathrm{~N}(\mathrm{p}=<0.001), \mathrm{C}_{\mathrm{n}} \mathrm{F}(\mathrm{p}=0.011), \mathrm{C}_{\mathrm{n}} \mathrm{P}(\mathrm{p}=0.006)$, and $\mathrm{C}_{\mathrm{n}} \mathrm{D}(\mathrm{p}=0.004)$ between killed and nonkilled enrichment cultures. After 90 days, the n-alkane and $\mathrm{C}_{\mathrm{n}} \mathrm{C}$ concentration in killed and non-killed enrichment cultures became significant with $\mathrm{p}=0.004$ and $\mathrm{p}=<0.001$, respectively.

Bay Jimmy aerobic enrichment culture results were consistent with the Fourchon results. After 120 days of aeration, n-alkanes, $\mathrm{C}_{n} \mathrm{C}, \mathrm{C}_{\mathrm{n}} \mathrm{D}, \mathrm{C}_{\mathrm{n}} \mathrm{P}, \mathrm{C}_{\mathrm{n}} \mathrm{F}$, and $\mathrm{C}_{\mathrm{n}} \mathrm{N}$ concentrations relative to hopane showed a total decrease of $51,38,84,83,93$, and $92 \%$, respectively (Figure 3.2). The reduction within each alkylated family is slightly lower in the Bay Jimmy enrichment cultures than the Fourchon enrichment cultures. After 30 days, there was a significant difference in $\mathrm{C}_{n} \mathrm{~N}(\mathrm{p}=0.004), \mathrm{C}_{\mathrm{n}} \mathrm{F}(\mathrm{p}=0.001), \mathrm{C}_{\mathrm{n}} \mathrm{P}(\mathrm{p}<0.001)$, and $\mathrm{C}_{\mathrm{n}} \mathrm{D}(\mathrm{p}=0.002)$ concentrations between killed and non-killed enrichment cultures. After 60 days the difference in n-alkane concentration between the killed and non-killed enrichment culture becomes significant $(p=0.018)$. There is no significant difference between $C_{n} C$ concentration in the Bay Jimmy killed and non-killed enrichment cultures throughout the 120-day experiment.

\subsubsection{Rate constants for PAH degradation}

To further investigate changes in the oil composition over the course of the aerobic experiments, first order rate constants (1/year) were determined for individual 
constituents in each set of enrichment cultures (Table 3.1). Although there is no significant difference between rate constants from the Fourchon and Bay Jimmy enrichment culture; however, rates in Fourchon marsh soils appear to be slightly faster. In the Fourchon enrichment culture set, $\mathrm{C}_{1} \mathrm{D}$ showed the highest rate constant. $\mathrm{C}_{1} \mathrm{P}, \mathrm{C}_{2} \mathrm{P}, \mathrm{C}_{3} \mathrm{P}, \mathrm{C}_{2} \mathrm{D}$, and $\mathrm{C}_{3} \mathrm{D}$ rate constants were the same order of magnitude as $\mathrm{C}_{1} \mathrm{D}$ but were $11,28,46,28$, and $52 \%$ lower, respectively. $\mathrm{C}_{4} \mathrm{P}, \mathrm{C}_{1} \mathrm{C}, \mathrm{C}_{2} \mathrm{C}$, and $\mathrm{C}_{3} \mathrm{C}$ exhibited the smallest rate constants, which were $82,82,85$, and $95 \%$ lower than the $\mathrm{C}_{1} \mathrm{D}$ rate constant, respectively. In the Bay Jimmy set, $\mathrm{C}_{1} \mathrm{P}$ exhibited the highest rate constant. $\mathrm{C}_{2} \mathrm{P}, \mathrm{C}_{1} \mathrm{D}$, and $\mathrm{C}_{2} \mathrm{D}$ rate constants were of the same order of magnitude as $\mathrm{C}_{1} \mathrm{P}$, but were $27 \%-33 \%$ lower. $\mathrm{C}_{3} \mathrm{P}, \mathrm{C}_{4} \mathrm{P}, \mathrm{C}_{3} \mathrm{D}, \mathrm{C}_{1} \mathrm{C}, \mathrm{C}_{2} \mathrm{C}$, and $\mathrm{C}_{3} \mathrm{C}$ showed $50 \%-87 \%$ lower rate constants when compared to $\mathrm{C}_{1} \mathrm{P}$. The only exception to the trend of slower loss rates with increased alkylation occurred within the chrysene family in the Bay Jimmy enrichment culture set where $C_{3} C$ had a faster loss rate than $C_{2} C$ and $\mathrm{C}_{1} \mathrm{C}$; however, rates for the alkylated chrysenes fall within the same margin of error.

The rate constants reported here are more than double of that reported for surface residue balls (SRBs) on the Port Fourchon and Elmer's Island beaches in 2011-2012 (Elango et al., 2014). Aerated slurries are likely to have higher rate constants because of the mixing and surplus of oxygen which lessen mass transfer and oxygen limitations, respectively. These results differ from field and laboratory PAH weathering patterns that were observed after an experimental oil spill on the shore of Deleware Bay (Venosa et al., 1996). In this study, parent and alkylated PAHs were reported relative to that compound's highest substituted homologue. First order rate constants were nearly identical in field and laboratory enrichment culture experiments. 
Table 3.1: First-order rate constants for declines in Fourchon and Bay Jimmy aerated enrichment cultures

\begin{tabular}{cccc}
\hline PAH & $\begin{array}{c}\text { Fourchon } \\
\text { rate } \\
(1 / \text { year })\end{array}$ & $\begin{array}{c}\text { Bay Jimmy } \\
\text { rate } \\
(1 / \text { year })\end{array}$ & $\begin{array}{c}\text { Significant } \\
\text { difference } \\
\text { between rates } \\
\text { from 2 sites? }\end{array}$ \\
\hline $\mathrm{C}_{1} \mathrm{P}$ & $16 \pm 1.5^{\mathrm{a}}$ & $15 \pm 3.4$ & No $(\mathrm{p}=0.772)$ \\
$\mathrm{C}_{2} \mathrm{P}$ & $13 \pm 1.1$ & $11 \pm 2.5$ & No $(\mathrm{p}=0.505)$ \\
$\mathrm{C}_{3} \mathrm{P}$ & $9.8 \pm 0.76$ & $7.5 \pm 1.6$ & No $(\mathrm{p}=0.264)$ \\
$\mathrm{C}_{4} \mathrm{P}$ & $3.3 \pm 0.59$ & $3.5 \pm 0.59$ & No $(\mathrm{p}=0.822)$ \\
$\mathrm{C}_{1} \mathrm{D}$ & $18 \pm 0.88$ & $12 \pm 2.4$ & No $(\mathrm{p}=0.079)$ \\
$\mathrm{C}_{2} \mathrm{D}$ & $13 \pm 1.4$ & $10 \pm 2.6$ & No $(\mathrm{p}=0.367)$ \\
$\mathrm{C}_{3} \mathrm{D}$ & $8.7 \pm 1.6$ & $5.2 \pm 0.89$ & No $(\mathrm{p}=0.129)$ \\
$\mathrm{C}_{1} \mathrm{C}$ & $3.2 \pm 0.40$ & $2.2 \pm 0.66$ & No $(\mathrm{p}=0.625)$ \\
$\mathrm{C}_{2} \mathrm{C}$ & $2.7 \pm 0.10$ & $1.9 \pm 0.57$ & No $(\mathrm{p}=0.239)$ \\
$\mathrm{C}_{3} \mathrm{C}$ & $.88 \pm 0.71$ & $2.6 \pm 0.79$ & No $(\mathrm{p}=0.093)$ \\
\hline
\end{tabular}

a \pm standard error

\subsubsection{Anaerobic enrichment culture results}

Anaerobic enrichment culture results using soil from Fourchon beach and Bay Jimmy are presented in Figures 3.3 and 3.4, respectively. Weathering ratios of alkylate PAHs (described in section 3.2.7) are used to determine if degradation is taking place. Neither the Fourchon marsh set [Figure 3.3(A-C)], nor the Fourchon mangrove enrichment culture set [Figure 3.3 (D-F)], showed any significant changes that would signify degradation over the course of the experiment for any of the treatments. In the Fourchon marsh enrichment culture study, $\Sigma \mathrm{C}_{n} \mathrm{P} / \Sigma \mathrm{C}_{n} \mathrm{C}, \Sigma \mathrm{C}_{\mathrm{n}} \mathrm{D} / \Sigma \mathrm{C}_{\mathrm{n}} \mathrm{C}$, and $\Sigma \mathrm{ALK} / \Sigma \mathrm{C}_{\mathrm{n}} \mathrm{C}$ ranged from $87-90 \%, 61-81 \%$, and 97-99\%, respectively. For the Fourchon mangrove study $\Sigma C_{n} P / \Sigma C_{n} C, \Sigma C_{n} D / \Sigma C_{n} C$, and $\Sigma A L K / \Sigma C_{n} \mathrm{C}$ ranged from $90-93 \%, 60-73 \%$, and $95-98 \%$, respectively. Similarly, the Bay Jimmy anaerobic enrichment culture set showed no significant changes in the weathering ratios of interest in any of the treatments throughout the course of the 

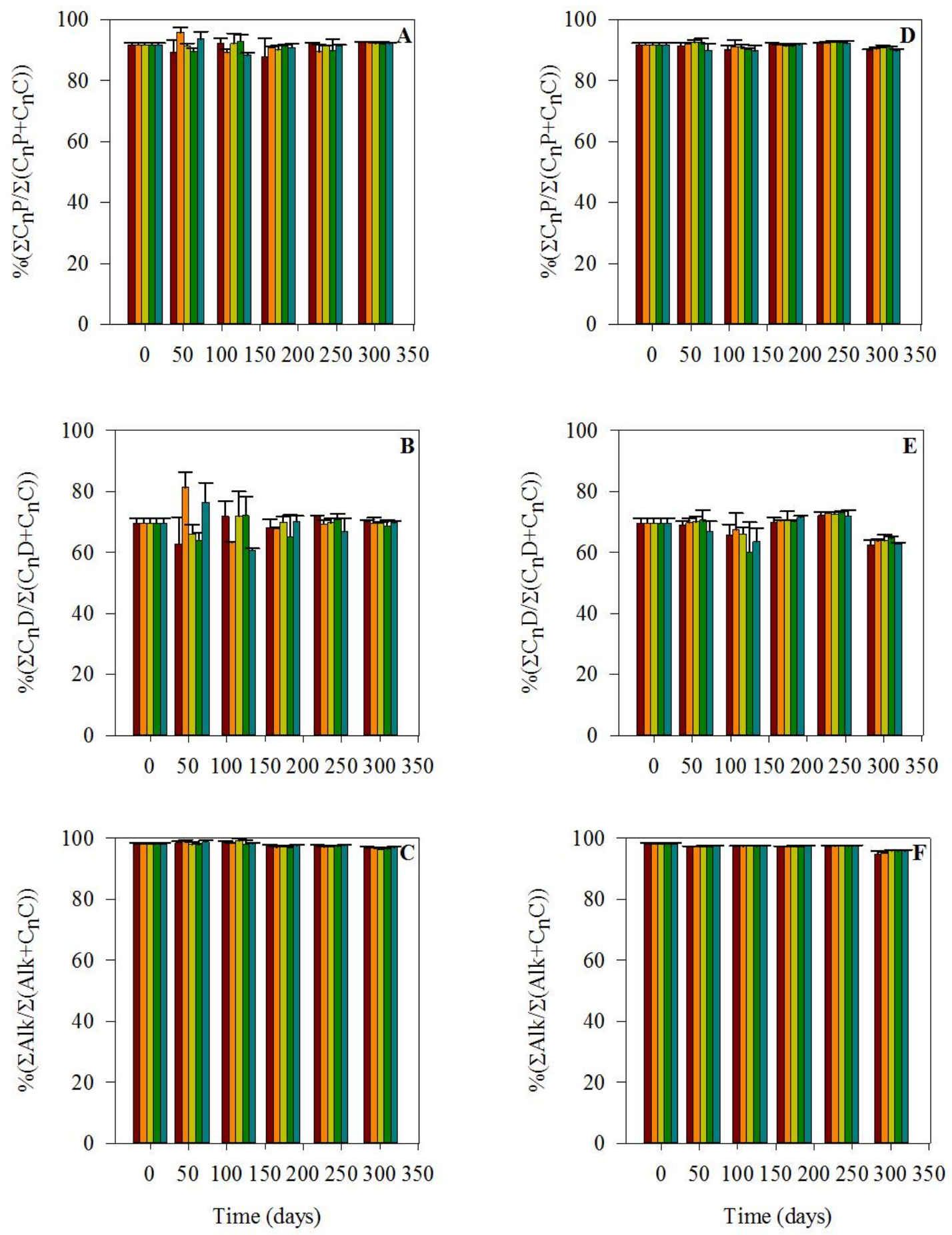

Figure 3.3. Percent change of total alkylated phenanthrenes (A,D), dibenzothiophenes $(\mathrm{B}, \mathrm{E})$ and n-alkanes $(\mathrm{C}, \mathrm{F})$ relative to alkylated chrysenes for 5 treatments in Fourchon beach marsh (A-C) and mangrove (D-F) enrichment cultures. 
$\square \mathrm{S}+\mathrm{N}$ amended Kill Control
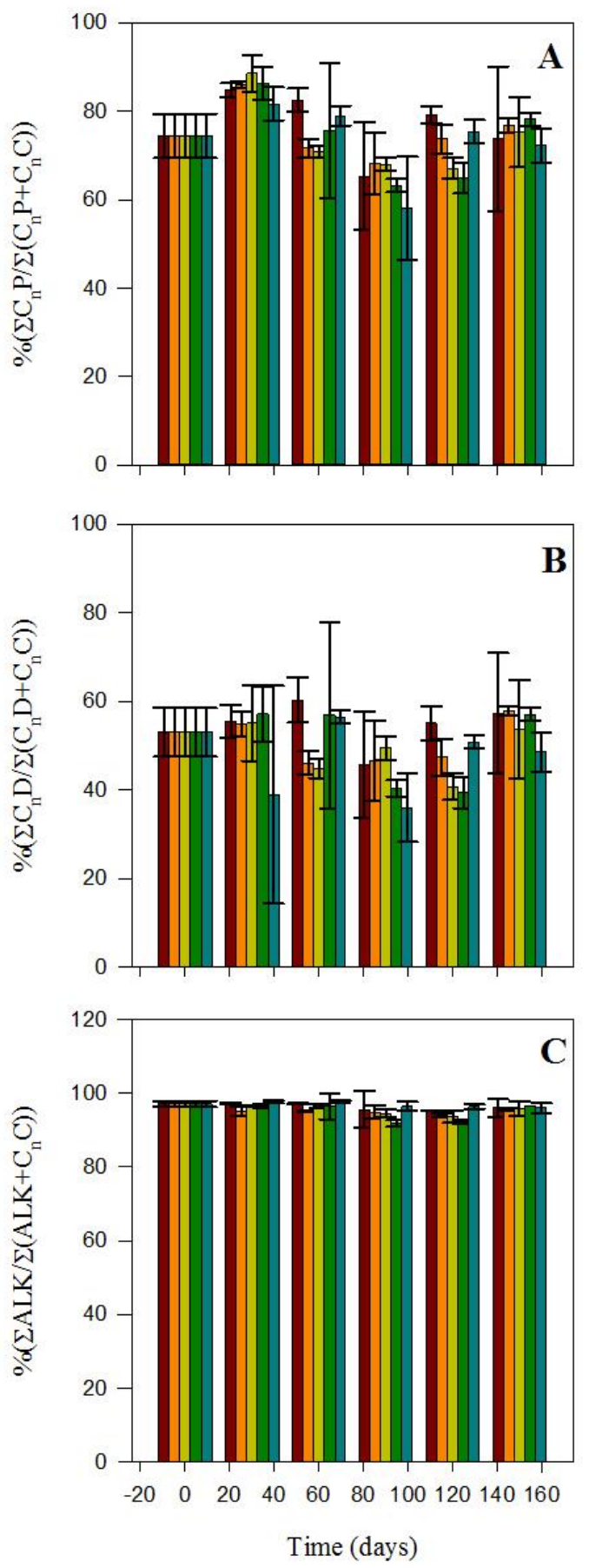

Figure 3.4. Percent change of total alkylated phenanthrenes (A), dibenzothiophenes (B) and $\mathrm{n}$-alkanes (C) relative to alkylated chrysenes for 5 treatments in Bay Jimmy marsh enrichment cultures. 
experiment (Figure 3.4). In the Bay Jimmy enrichment cultures, $\Sigma C_{n} P / \Sigma C_{n} C, \Sigma C_{n} D / \Sigma C_{n} C$, and $\Sigma A L K / \Sigma C_{n} C$ ranged from $58-89 \%, 36-60 \%$, and $92-98 \%$, respectively. The values observed for these key ratios were comparable in all anaerobic enrichment cultures.

Although there was no noticeable degradation of the oil constituents of interest in the anaerobic enrichment cultures, nutrient and electron acceptor data collected during each sampling period demonstrates the microbial redox process linked with respiration. Sulfate levels in the Fourchon beach marsh and mangrove enrichment cultures are $74 \%$ higher at the beginning of the experiment than the Bay Jimmy marsh samples because of its more inland location in the estuary. Sulfate loss ranged from $92-96 \%$ for all non-killed Fourchon beach marsh and mangrove enrichment culture treatments after 174 days [Figures $3.5(\mathrm{~A}, \mathrm{D})]$. For the killed control samples in the Fourchon beach experiments, sulfate concentrations increased by $16 \%$ after 174 days in both sets. In the Bay Jimmy enrichment culture study, sulfate decreased by $76-93 \%$ in non-killed treatments and by $43 \%$ in killed treatments. Sulfate reduction is the most likely electron acceptor in the absence of oxygen and respiration of some crude oil components can be linked to it.

In all sets of anaerobic enrichment cultures, similar trends of porewater ammonium-N and P over time was observed. For nitrogen-amended treatments, ammonium was spiked to $100 \mathrm{mg}-\mathrm{N} / \mathrm{L}$ and was maintained at a concentration above $40 \mathrm{mg}-\mathrm{N} / \mathrm{L}$ until the end of the experiment. In treatments where $\mathrm{N}$ was not added, porewater $\mathrm{N}$ concentration in each enrichment culture stayed above $2 \mathrm{mg}-\mathrm{N} / \mathrm{L}$. Nitrogen did not appear to become limiting in any of the anaerobic enrichment culture experiments [Figure 3.5 (B,E) and Figure $3.6(\mathrm{~B})$ ]. Phosphorous in the Fourchon enrichments increased by $280-430 \%$ over the course of the experiment. In the Fourchon marsh set, pore water P concentrations for non-killed 
$\longrightarrow$ Natural Attenuation $\longrightarrow \mathrm{S}$ amended $\longrightarrow \mathrm{N}$ amended

$\rightarrow-\mathrm{S}+\mathrm{N}$ amended $\longrightarrow$ - Kill Control
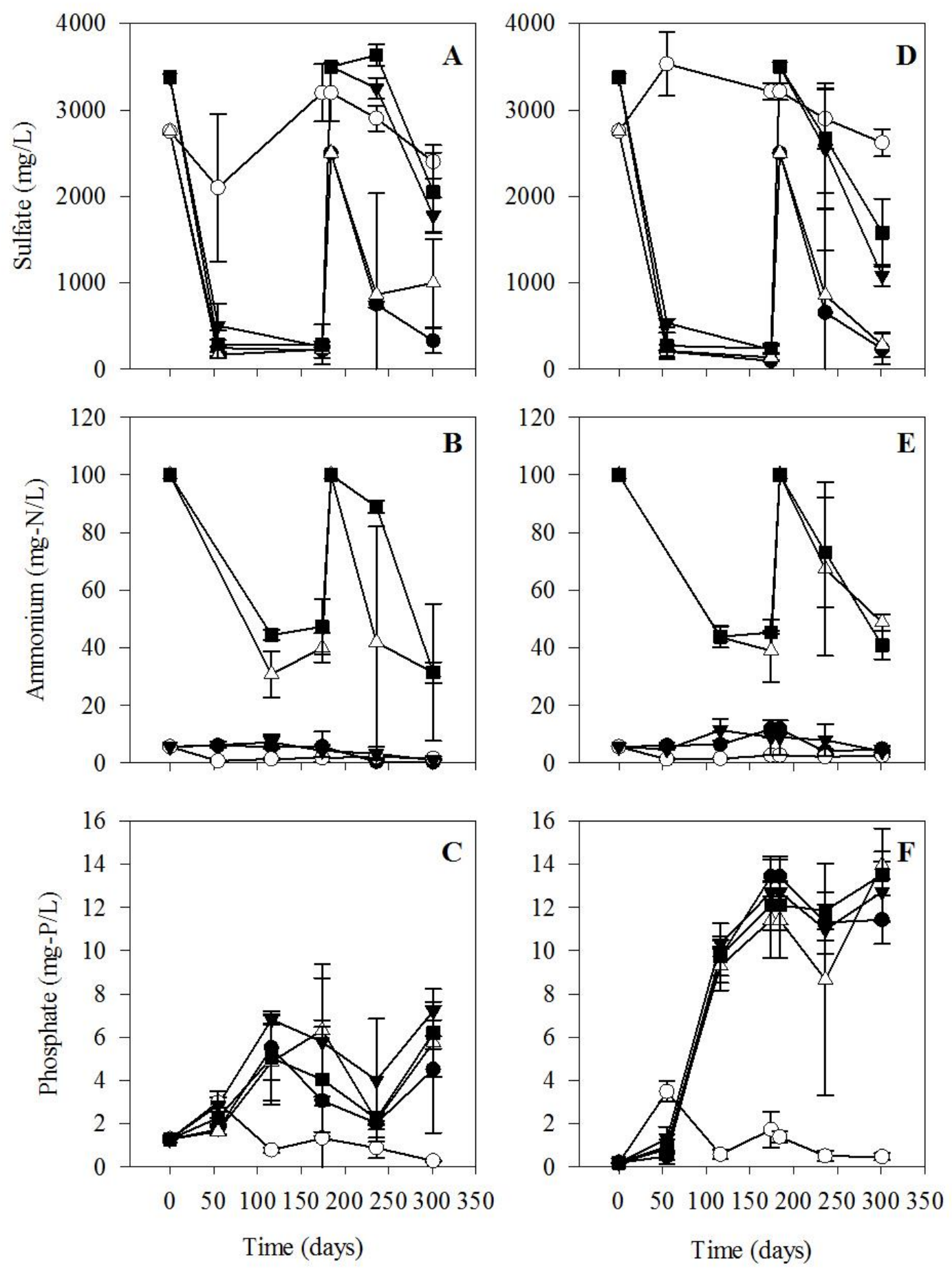

Figure 3.5. Sulfate $(A, D)$, ammonium-N (B,E), and phosphate-P (C,F) concentration versus time for 5 treatments in Fourchon marsh (A-C) and mangrove (D-F) anaerobic enrichment cultures 
$\longrightarrow$ Natural Attenuation $\longrightarrow \mathrm{S}$ amended $\longrightarrow \sim \mathrm{N}$ amended

$\rightarrow-\mathrm{S}+\mathrm{N}$ amended $\longrightarrow$ Kill Control
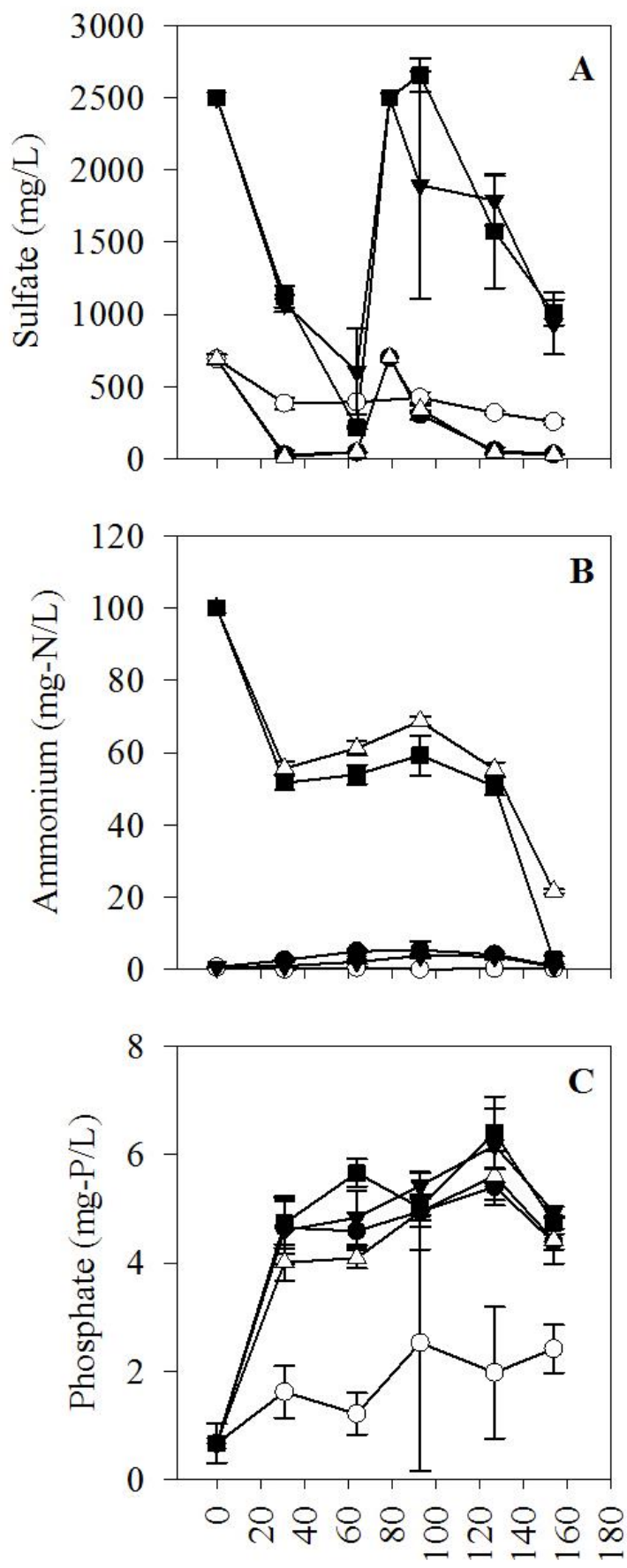

Time (days)

Figure 3.6. Sulfate (A), ammonium-N (B), and phosphate-P (C) concentration versus time for 5 treatments in Bay Jimmy marsh anaerobic enrichment cultures 
samples increased killed sample increased by $4.1 \%$ after 116 days [Figure 3.5(C)]. The Fourchon mangrove enrichment culture set showed larger pore water P increases ranging from $5,300-4,800 \%$ for non-killed samples and $200 \%$ for killed samples after 116 days [Figure 3.5(F)]. For the Bay Jimmy marsh set porewater P increases ranged from 720$870 \%$ in non-killed treatments and $200 \%$ for the killed treatment. Porewater P concentration increases can be attributed to the release of iron and aluminum-bound phosphates during a change in redox potential driven by the use of iron as an electron acceptor. Taken together these results indicate that sulfate is the electron acceptor and that $\mathrm{N}$ and $\mathrm{P}$ are not limiting degradation. Therefore, the absence of oxygen is the key biogeochemical parameter preventing biodegradation of MC252-derived PAHs.

\subsubsection{Enrichment culture rates and field weathering}

Results from the aerobic and anaerobic enrichment culture studies indicate that availability of oxygen allow MC252-derived alkylated PAHs to degrade at rates as high as $\sim 10$ year-1 (i.e., $\mathrm{C}_{1} \mathrm{P}$ ). Previous studies by these investigators (Rodrigue et al., 2014) measured field-based weathering ratios in these same locations that measure, in a single index, losses of 3-ring PAHs such as phenanthrenes and dibenzothiophenes relative to alkylated chrysenes. For the Fourchon Beach and Bay Jimmy marsh sites changes in these dibenzothiophenes, relative to chrysenes, when considered as a group $\left(\mathrm{C}_{1} \mathrm{P}-\mathrm{C}_{4} \mathrm{P}\right.$ or $\mathrm{C}_{1} \mathrm{D}-$ $C_{3} \mathrm{D}$ ) (Rodrigue et al., 2014). These changes in weathering ratios are substantially lower than predicted, if rate constants measured in the aerobic enrichment cultures were weathering ratios has averaged about $5 \%$ per year for the alkylated phenanthrenes and 
applicable to the field. On a simple half-life basis, aerobic rate constants for phenanthrenes $\left(\sim 10 \mathrm{yr}^{-1}\right)$ translate to a half-life of a month while weathering ratios indicate a half-life of a decade.

Differences in enrichment culture and field rates are common and can result from mass transfer limitations or differences in a key environmental condition such as nutrient status, temperature or the availability of electron acceptors. The contrast between the PAH biodegradation in the aerobic and anaerobic enrichment cultures and the tidal nature of the systems under study, suggests that oxygen availability in the marsh is causing these differences in potential rate versus the observed rate. If this is true, one hypothesis is that aerobic biodegradation is occurring only during periods of extremely low tides which expose the surface and the oiled layer $(0-5 \mathrm{~cm})$ (Rodrigue et al., in review) to oxygen. The changes in weathering ratio from the field measurements are consistent with an aerobic rate occurring a few days a year. In these Barataria Bay systems with a low tidal range, northerly winds drive water completely out of the marsh during the winter months (Connor and Day, 1987). These periods may provide opportunities for aerobic biodegradation processes observed above.

\subsection{Conclusion and Implications}

$\mathrm{PAH}$ and n-alkane concentrations relative to C30-Hopane are reduced in both Fourchon and Bay Jimmy aerobic enrichment culture experiments. Killed samples in these studies show reduction of these oil components but to a much lesser extent. Losses in these killed samples can be attributed to physical weathering process rather than biodegradation. In these aerobic slurries, first-order rate constants decrease with increased alkylation within 
PAH homologue groups. Similarly, first order rate constants decrease with the increase of molecular weights of the compound groups.

Anaerobic enrichment culture results show no significant decrease in PAH and n-alkanes after 301 and 154 days in Fourchon and Bay Jimmy experiments, respectively. Increasing pore water sulfate, ammonium, phosphorous, or ammonium and phosphorous showed no effect on oil weathering in these experiments. Similarly, the killing of the microbial population did not affect oil weathering. Although there was no degradation observed, sulfate reduction was observed in all non-killed enrichment culture treatments. This sulfate reduction was accompanied by increases in phosphorous concentrations similar to dialysis sampler field data outlined in chapter 2 . This increase in phosphorous is driven by a change in redox potential causing the release of iron and aluminum bound phosphates during iron reduction. In kill control treatments, pore water sulfate concentrations were not reduced and phosphorous concentrations were not increased as they did in non-killed samples. This data indicates that there is an active microbial community; however, PAHs and n-alkanes were not the preferred carbon source.

Biodegradation is an important process in the reduction of oil in contaminated marsh and mangrove sediments. This process is heavily dependent on the redox potential of the surrounding environment. Aerobic biodegradation processes are faster and more efficient than anaerobic processes. Tidal fluxes may allow oxygen to penetrate into oil contaminated soils in these wetland systems. If oxygen is not allowed to penetrate into these contaminated soils, PAHs and n-alkanes may persist for many years to come. 


\section{CHAPTER 4: SUMMARY AND OUTLOOK}

\subsection{Experimental Findings and Implications}

There are a number of conclusions that can be drawn from the information presented in this thesis. Measurable weathering of MC252 oil is taking place in coastal Louisiana salt marsh and mangrove systems. Oiling was found to be minimal below $10 \mathrm{~cm}$ depths. Total alkylated phenanthrenes and dibenzothiophenes accounted for the largest percentage of remaining PAHs at Fourchon and Bay Jimmy locations. These compounds were found to be weathering at a rate of $5 \%$ a year relative to alkylated chrysenes with less alkylated PAHs showing faster rates of weathering than more alkylated PAHs. Lower $\delta^{13} \mathrm{C}$ signatures of evolved $\mathrm{CO}_{2}$ suggest mineralization of hydrocarbons along with the indigenous organic matter. Carbon mineralization can only occur through microbial processes. Microbial degradation processes are not hindered by a lack of nitrogen or phosphorous in these marsh systems. Also, in the absence of oxygen, there is plenty of sulfate available to be used as a terminal electron acceptor. Hydrocarbon biodegradation coupled with sulfate reduction may be contributing to zones of sulfate depletion at some field locations.

In aerobic slurries, natural-attenuation, enrichment culture studies, alkylated PAHs and n-alkanes showed significant weathering which contrasted significantly from samples where the microbial population was killed. First order loss rates, determined for individual alkylated PAH groups, were inversely proportion to levels of alkylation. No significant decrease of PAHs or n-alkanes was observed in anaerobic, enrichment culture studies under any treatments although sulfate reduction was observed suggesting an active microbial population. Anaerobic biodegradation may require longer periods of time to undergo noticeable reduction these specific alkylated PAHs and n-alkanes. 


\subsection{Future Research}

Future research of Louisiana marsh and mangrove wetlands is needed to observe the biogeochemical controls of different contaminated sites to determine if the conditions are favorable for biodegradation processes. $\mathrm{CO}_{2}$ flux chamber experiments could be deployed in a more year-round type experiment to observe changes in the mineralization rates at several different times of the year. Seasonal changes in pore water nutrient and electron acceptor concentrations may be playing a larger role in biodegradation rates than witnessed in this study. Tracking weathering rates of heavier, more-alkylated PAHs and longer chained n-alkanes may need to be done over the course of several years because of their persistence observed in this study. Likewise, laboratory enrichment culture studies should be observed over longer periods of time to see if biodegradation will take place. Soil samples from field and enrichment culture samples should be extracted for DNA to see if known PAH degraders are present in these samples. 


\section{REFERENCES}

Aeppli, C., Carmichael, C.A., Nelson, R.K., Lemkau, K.L., Graham, W.M., Redmond, M.C., Valentine, D.L., Reddy, C.M., 2012. Oil Weathering after the Deepwater Horizon Disaster Led to the Formation of Oxygenated Residues. Environmental Science \& Technology 46, 8799-8807.

Anderson, C., 2013. Degradation and Composition of Polycyclic Aromatic Hydrocarbons (PAHs) Following Oil Exposure in Experimental Salt Marshes. Water, Air, \& Soil Pollution 224, 1-13.

Anderson, C.J., Hess, T.A., 2012. The effects of oil exposure and weathering on black-needle rush $(<\mathrm{i}>$ Juncus roemerianus $</ \mathrm{i}>$ ) marshes along the Gulf of Mexico. Marine pollution bulletin 64, 2749-2755.

Annweiler, E., Materna, A., Safinowski, M., Kappler, A., Richnow, H.H., Michaelis, W., Meckenstock, R.U., 2000. Anaerobic degradation of 2-methylnaphthalene by a sulfatereducing enrichment culture. Applied and environmental microbiology 66, 5329-5333.

Atlas, R.M., 1981. Microbial degradation of petroleum hydrocarbons: an environmental perspective. Microbiological reviews 45, 180.

Atlas, R.M., Hazen, T.C., 2011. Oil biodegradation and bioremediation: a tale of the two worst spills in U.S. history. Environ. Sci. Technol. 45, 6709-6715.

Bauer, J.E., Capone, D.G., 1985. Degradation and Mineralization of the Polycyclic Aromatic Hydrocarbons Anthracene and Naphthalene in Intertidal Marine Sediments. Applied and Environmental Microbiology 50, 81-90.

Bayona, J.M., Albaigés, J., Solanas, A.M., Pares, R., Garrigues, P., Ewald, M., 1986. Selective Aerobic Degradation of Methyl-Substituted Polycyclic Aromatic Hydrocarbons in Petroleum by Pure Microbial Culturest. International Journal of Environmental Analytical Chemistry 23, 289-303.

Bergmann, F.D., Selesi, D., Meckenstock, R.U., 2011. Identification of new enzymes potentially involved in anaerobic naphthalene degradation by the sulfate-reducing enrichment culture N47. Archives of microbiology 193, 241-250.

Boopathy, R., Shields, S., Nunna, S., 2012. Biodegradation of crude oil from the BP oil spill in the marsh sediments of Southeast Louisiana, USA. Appl. Biochem. Biotech. 167, 15601568.

Bossert, I., Bartha, R., 1984. The fate of petroleum in soil ecosystems. 
Caldwell, M.E., Garrett, R.M., Prince, R.C., Suflita, J.M., 1998. Anaerobic biodegradation of long-chain n-alkanes under Sulfate-reducing conditions. Environ. Sci. Technol. 32, 21912195.

Cerniglia, C.E., 1992. Biodegradation of polycyclic aromatic hydrocarbons. Biodegradation 3, 351-368.

Cerniglia, C.E., 1993. Biodegradation of polycyclic aromatic hydrocarbons. Current Opinion in Biotechnology 4, 331-338.

Cerniglia, C.E., Heitkamp, M.A., 1989. Microbial degradation of polycyclic aromatic hydrocarbons (PAH) in the aquatic environment. Metabolism of polycyclic aromatic hydrocarbons in the aquatic environment. CRC Press, Inc., Boca Raton, Fla, 41-68.

Chang, B.V., Shiung, L.C., Yuan, S.Y., 2002. Anaerobic biodegradation of polycyclic aromatic hydrocarbon in soil. Chemosphere 48, 717-724.

Chen, J., Zhang, H., Huang, H., Li, X., Shi, S., Liu, F., Chen, L., 2013. Impact of anaerobic biodegradation on alkylphenanthrenes in crude oil. Organic Geochemistry 61, 6-14.

Chmura, G., Aharon, P., Socki, R., Abernethy, R., 1987. An inventory of 13C abundances in coastal wetlands of Louisiana, USA: vegetation and sediments. Oecologia 74, 264-271.

Coates, J.D., Anderson, R.T., Lovley, D.R., 1996. Oxidation of Polycyclic Aromatic Hydrocarbons under Sulfate-Reducing Conditions. Applied and Environmental Microbiology 62, 1099-1101.

Coates, J.D., Woodward, J., Allen, J., Philp, P., Lovley, D.R., 1997. Anaerobic degradation of polycyclic aromatic hydrocarbons and alkanes in petroleum-contaminated marine harbor sediments. Applied and Environmental Microbiology 63, 3589-3593.

Command, D.H.U., 2011. US scientific teams refine estimates of oil flow from BP's well prior to capping. Gulf of Mexico Oil Spill Response 2010.

Commision, O.S., 2011. The gulf oil disaster and the future of offshore drilling, Report to the President [of the USA].

Deines, P., Fritz, P., Fontes, J.C., 1980. Handbook of environmental isotope geochemistry. The Terrestrial Environment 1, 329-406.

Diercks, A.R., Highsmith, R.C., Asper, V.L., Joung, D.J., Zhou, Z.Z., Guo, L.D., Shiller, A.M., Joye, S.B., Teske, A.P., Guinasso, N., Wade, T.L., Lohrenz, S.E., 2010. Characterization of subsurface polycyclic aromatic hydrocarbons at the Deepwater Horizon site. Geophysical Research Letters 37. 
Elango, V., Urbano, M., Lemelle, K.R., Pardue, J.H., 2014. Biodegradation of MC252 oil in oil:sand aggregates in a coastal headland beach environment. Frontiers in Microbiology 5 .

Foght, J., Westlake, D., 1987. Biodegradation of hydrocarbons in freshwater. Oil in Freshwater: Chemistry, Biology, Countermeasure Technology. Pergamon Press, New York, NY 1987. Edited by John H. Vandermeulen and Steve E. Hrudey. p 217-230, 3 tab, 59 ref.

Georgiou, I.Y., FitzGerald, D.M., Stone, G.W., 2005. The impact of physical processes along the Louisiana coast. Journal of Coastal Research.

Gibson, D.T., 1984. Microbial degradation of organic compounds. Marcel dekker.

Griebler, C., Safinowski, M., Vieth, A., Richnow, H.H., Meckenstock, R.U., 2003. Combined application of stable carbon isotope analysis and specific metabolites determination for assessing in situ degradation of aromatic hydrocarbons in a tar oil-contaminated aquifer. Environmental Science \& Technology 38, 617-631.

Hasinger, M., Scherr, K.E., Lundaa, T., Bräuer, L., Zach, C., Loibner, A.P., 2012. Changes in isoand $\mathrm{n}$-alkane distribution during biodegradation of crude oil under nitrate and sulphate reducing conditions. Journal of Biotechnology 157, 490-498.

Hayes, L.A., Lovley, D.R., 2002. Specific 16S rDNA Sequences Associated with Naphthalene Degradation under Sulfate-Reducing Conditions in Harbor Sediments. Microbial Ecology $43,134-145$.

Hayworth, J., Clement, T., Valentine, J., 2011. Deepwater Horizon oil spill impacts on Alabama beaches. Hydrology \& Earth System Sciences Discussions 8.

Head, I.M., Swannell, R.P.J., 1999. Bioremediation of petroleum hydrocarbon contaminants in marine habitats. Current Opinion in Biotechnology 10, 234-239.

Heitkamp, M.A., Freeman, J.P., Miller, D.W., Cerniglia, C.E., 1988. Pyrene degradation by a Mycobacterium sp. -identification of ring oxidation and ring fission-products Applied and Environmental Microbiology 54, 2556-2565.

Hesslein, R.H., 1976. An in situ sampler for close interval pore water studies. Limnology and Oceanography 21, 912-914.

Horel, A., Mortazavi, B., Sobecky, P., 2012. Seasonal monitoring of Hydrocarbon degraders in Alabama marine ecosystems following the Deepwater Horizon oil spill. Water Air Soil Poll. 223, 3145-3154.

Jackson, A., Pardue, J., 1999a. Quantifying the mineralization of contaminants using stable carbon isotope ratios. Organic Geochemistry 30, 787-792. 
Jackson, A.W., Pardue, J.H., Araujo, R., 1996. Monitoring crude oil mineralization in salt marshes: use of stable carbon isotope ratios. Environmental Science \& Technology 30, 1139-1144.

Jackson, A.W., Pardue, J.H., 1999b. Potential for enhancement of biodegradation of crude oil in Louisiana salt marshes usingnutrient amendments. Water Air Soil Poll. 109, 343-355.

Jørgensen, B., Bang, M., Blackburn, T.H., 1990. Anaerobic mineralization in marinesediments from the Baltic-Sea-North-Sea transition. Marine Ecology-Progress Series 59, 39-54.

Leahy, J.G., Colwell, R.R., 1990. Microbial degradation of hydrocarbons in the environment. Microbiol. Rev. 54, 305-315.

Lei, L., Khodadoust, A., Suidan, M., Tabak, H., 2005. Biodegradation of sediment-bound PAHs in field-contaminated sediment. Water Research 39, 349-361.

Lin, Q., Mendelssohn, I.A., 2012. Impacts and recovery of the Deepwater Horizon Oil Spill on vegetation structure and function of coastal salt marshes in the Northern Gulf of Mexico. Environ. Sci. Technol. 46, 3737-3743.

Liu, Z., Liu, J., Zhu, Q., Wu, W., 2012. The weathering of oil after the Deepwater Horizon oil spill: insights from the chemical composition of the oil from the sea surface, salt marshes and sediments. Environmental Research Letters 7, 035302.

Mahmoudi, N., Porter, T.M., Zimmerman, A.R., Fulthorpe, R.R., Kasozi, G.N., Silliman, B.R., Slater, G.F., 2013. Rapid degradation of Deepwater Horizon spilled oil by indigenous microbial communities in Louisiana saltmarsh sediments. Environmental Science \& Technology 47, 13303-13312.

McClenachan, G., Turner, R.E., Andrew, W.T., 2013. Effects of oil on the rate and trajectory of Louisiana marsh shoreline erosion. Environmental Research Letters 8, 044030.

McNally, D.L., Mihelcic, J.R., Lueking, D.R., 1998. Biodegradation of Three- and Four-Ring Polycyclic Aromatic Hydrocarbons under Aerobic and Denitrifying Conditions. Environmental Science \& Technology 32, 2633-2639.

McNutt, M.K., Camilli, R., Crone, T.J., Guthrie, G.D., Hsieh, P.A., Ryerson, T.B., Savas, O., Shaffer, F., 2011. Review of flow rate estimates of the Deepwater Horizon oil spill. P. Natl. Acad. Sci. .

Mendelssohn, I.A., Andersen, G.L., Baltz, D.M., Caffey, R.H., Carman, K.R., Fleeger, J.W., Joye, S.B., Lin, Q., Maltby, E., Overton, E.B., 2012. Oil impacts on coastal wetlands: implications for the Mississippi River Delta ecosystem after the Deepwater Horizon oil spill. BioScience 62, 562-574. 
Mercer, K., Trevors, J., 2011. Remediation of oil spills in temperate and tropical coastal marine environments. Environmentalist 31, 338-347.

Michel, J., Owens, E.H., Zengel, S., Graham, A., Nixon, Z., Allard, T., Holton, W., Reimer, P.D., Lamarche, A., White, M., 2013. Extent and degree of shoreline oiling: Deepwater Horizon oil spill, Gulf of Mexico, USA. PloS one 8, e65087.

Moody, R.M., Cebrian, J., Heck Jr, K.L., 2013. Interannual recruitment dynamics for resident and transient marsh species: evidence for a lack of impact by the Macondo oil spill. PloS one 8, e58376.

Natter, M., Keevan, J., Wang, Y., Keimowitz, A.R., Okeke, B.C., Son, A., Lee, M.-K., 2012. Level and degradation of Deepwater Horizon spilled oil in coastal marsh sediments and porewater. Environ. Sci. Technol. 46, 5744-5755.

Peacock, E.E., Hampson, G.R., Nelson, R.K., Xu, L., Frysinger, G.S., Gaines, R.B., Farrington, J.W., Tripp, B.W., Reddy, C.M., 2007. The 1974 spill of the Bouchard 65 oil barge: Petroleum hydrocarbons persist in Winsor Cove salt marsh sediments. Marine Pollution Bulletin 54, 214-225.

Prince, R.C., Elmendorf, D.L., Lute, J.R., Hsu, C.S., Haith, C.E., Senius, J.D., Dechert, G.J., Douglas, G.S., Butler, E.L., 1994. 17.alpha.(H)-21.beta.(H)-hopane as a conserved internal marker for estimating the biodegradation of crude oil. Environmental Science \& Technology 28, 142-145.

Reddy, C.M., Arey, J.S., Seewald, J.S., Sylva, S.P., Lemkau, K.L., Nelson, R.K., Carmichael, C.A., McIntyre, C.P., Fenwick, J., Ventura, G.T., Van Mooy, B.A.S., Camilli, R., 2011. Composition and fate of gas and oil released to the water column during the Deepwater Horizon oil spill. P. Natl. Acad. Sci.

Rockne, K.J., Chee-Sanford, J.C., Sanford, R.A., Hedlund, B.P., Staley, J.T., Strand, S.E., 2000. Anaerobic Naphthalene Degradation by Microbial Pure Cultures under Nitrate-Reducing Conditions. Applied and Environmental Microbiology 66, 1595-1601.

Rockne, K.J., Strand, S.E., 1998. Biodegradation of Bicyclic and Polycyclic Aromatic Hydrocarbons in Anaerobic Enrichments. Environmental Science \& Technology 32, 3962-3967.

Rodrigue, M.P., Pardue, J.H., Elango, V., Jackson, A., in review. Biodegradation of MC252 polycyclic cromatic hydrocarbons and alkanes in three coastal wetlands.

Ryerson, T.B., Camilli, R., Kessler, J.D., Kujawinski, E.B., Reddy, C.M., Valentine, D.L., Atlas, E., Blake, D.R., de Gouw, J., Meinardi, S., Parrish, D.D., Peischl, J., Seewald, J.S., Warneke, C., 2012. Chemical data quantify Deepwater Horizon hydrocarbon flow rate and environmental distribution. Proceedings of the National Academy of Sciences 109, 20246-20253. 
Santos, H., Carmo, F., Paes, J., Rosado, A., Peixoto, R., 2011. Bioremediation of mangroves impacted by petroleum. Water Air Soil Poll. 216, 329-350.

Shin, W.S., Pardue, J.H., Jackson, W.A., 2000. Oxygen demand and sulfate reduction in petroleum hydrocarbon contaminated salt marsh soils. Water Research 34, 1345-1353.

Shin, W.S., Pardue, J.H., Jackson, W.A., Choi, S.J., 2001. Nutrient Enhanced Biodegradation of Crude Oil in Tropical Salt Marshes. Water Air Soil Poll. 131, 135-152.

Silliman, B.R., van de Koppel, J., McCoy, M.W., Diller, J., Kasozi, G.N., Earl, K., Adams, P.N., Zimmerman, A.R., 2012. Degradation and resilience in Louisiana salt marshes after the BP-Deepwater Horizon oil spill. Proceedings of the National Academy of Sciences 109, 11234-11239.

Tate, P., Shin, W., Pardue, J., Jackson, W., 2012. Bioremediation of an experimental oil spill in a coastal Louisiana salt marsh. Water Air Soil Poll. 223, 1115-1123.

Upton, H.F., 2011. The Deepwater Horizon oil spill and the Gulf of Mexico fishing industry. Congressional Research Service, Library of Congress.

Urbano, M., Elango, V., Pardue, J.H., 2013a. Biogeochemical characterization of MC252 oil:sand aggregates on a coastal headland beach. Marine Pollution Bulletin 77, 183-191.

Venosa, A.D., Suidan, M.T., Wrenn, B.A., Strohmeier, K.L., Haines, J.R., Eberhart, B.L., King, D., Holder, E., 1996. Bioremediation of an experimental oil spill on the shoreline of Delaware Bay. Environ. Sci. Technol. 30, 1764-1775.

Venosa, A.D., Zhu, X., 2003. Biodegradation of crude oil contaminating marine shorelines and freshwater wetlands. Spill Sci. Technol. B. 8, 163-178.

Wang, Z., Fingas, M., Blenkinsopp, S., Sergy, G., Landriault, M., Sigouin, L., Foght, J., Semple, K., Westlake, D.W.S., 1998. Comparison of oil composition changes due to biodegradation and physical weathering in different oils. Journal of Chromatography A 809, 89-107.

Whitehead, A., Dubansky, B., Bodinier, C., Garcia, T.I., Miles, S., Pilley, C., Raghunathan, V., Roach, J.L., Walker, N., Walter, R.B., Rice, C.D., Galvez, F., 2012. Genomic and physiological footprint of the Deepwater Horizon oil spill on resident marsh fishes. Proceedings of the National Academy of Sciences 109, 20298-20302.

Wrenn, B.A., Haines, J.R., Venosa, A.D., Kadkhodayan, M., Suidan, M.T., 1994. Effects of nitrogen source on crude oil biodegradation. Journal of Industrial Microbiology 13, 279286.

Yu, J., Tao, R., Yu, K., 2012. Anaerobic biodegradation of benzene in salt marsh sediment of the Louisiana Gulf coast. Ecol. Eng. 40, 6-10. 
Zhang, X., Sullivan, E., Young, L.Y., 2000. Evidence for aromatic ring reduction in the biodegradation pathwayof carboxylated naphthalene by a sulfate reducing consortium. Biodegradation 11, 117-124. 
APPENDIX A. PAH WR FROM FOURCHON MARSH FIELD SAMPLES FOR FIGURE 1

\begin{tabular}{ccccccccc}
\hline & \multicolumn{2}{c}{$8 / 11 / 2011$} & \multicolumn{2}{c}{$7 / 26 / 2012$} & \multicolumn{2}{c}{$1 / 7 / 2013$} & \multicolumn{2}{c}{$11 / 7 / 2013$} \\
& WR & Stdev & WR & Stdev & WR & Stdev & WR & Stdev \\
\hline $\mathrm{C}_{0} \mathrm{~N}$ & 6.56 & 2.07 & 4.41 & 4.80 & & & 3.91 & \\
$\mathrm{C}_{1} \mathrm{~N}$ & 5.18 & 1.94 & 2.96 & 0.85 & 6.56 & 5.32 & 6.11 & 2.92 \\
$\mathrm{C}_{2} \mathrm{~N}$ & 4.41 & 2.03 & 1.98 & 1.14 & 5.78 & 6.57 & 2.37 & 0.95 \\
$\mathrm{C}_{3} \mathrm{~N}$ & 7.10 & 2.10 & 0.18 & 0.35 & 0.23 & 0.45 & 3.32 & 2.43 \\
$\mathrm{C}_{4} \mathrm{~N}$ & 11.57 & 5.15 & 0.09 & 0.18 & & & 2.85 & 2.64 \\
$\mathrm{C}_{0} \mathrm{~F}$ & 0.00 & 0.00 & 0.07 & 0.14 & 0.00 & 0.00 & 0.00 & 0.00 \\
$\mathrm{C}_{1} \mathrm{~F}$ & 7.46 & 3.69 & 0.52 & 0.75 & 0.74 & 1.49 & 0.49 & 0.53 \\
$\mathrm{C}_{2} \mathrm{~F}$ & 6.88 & 2.26 & 2.37 & 3.03 & 6.39 & 5.42 & 5.33 & 0.65 \\
$\mathrm{C}_{3} \mathrm{~F}$ & 9.76 & 3.28 & 11.00 & 2.76 & 10.13 & 10.23 & 9.80 & 2.46 \\
$\mathrm{C}_{0} \mathrm{P}$ & 4.12 & 1.24 & 1.45 & 0.55 & 3.31 & 2.41 & 1.39 & 1.00 \\
$\mathrm{C}_{1} \mathrm{P}$ & 22.97 & 4.65 & 3.17 & 2.28 & 7.07 & 0.20 & 2.29 & 1.28 \\
$\mathrm{C}_{2} \mathrm{P}$ & 42.54 & 6.07 & 29.75 & 8.52 & 42.07 & 7.07 & 27.06 & 3.07 \\
$\mathrm{C}_{3} \mathrm{P}$ & 40.14 & 4.86 & 40.30 & 10.35 & 55.38 & 7.46 & 38.53 & 2.60 \\
$\mathrm{C}_{4} \mathrm{P}$ & 34.44 & 1.78 & 51.53 & 4.65 & 47.71 & 5.47 & 30.25 & 2.82 \\
$\mathrm{C}_{0} \mathrm{D}$ & 0.00 & 0.00 & 0.00 & 0.00 & & & 0.00 & 0.00 \\
$\mathrm{C}_{1} \mathrm{D}$ & 14.31 & 3.74 & 0.19 & 0.38 & 0.29 & 0.43 & 5.37 & 3.85 \\
$\mathrm{C}_{2} \mathrm{D}$ & 18.99 & 3.90 & 14.66 & 4.06 & 23.90 & 8.91 & 15.45 & 2.46 \\
$\mathrm{C}_{3} \mathrm{D}$ & 24.51 & 3.17 & 31.80 & 7.39 & 35.25 & 5.54 & 23.44 & 2.48 \\
$\mathrm{C}_{0} \mathrm{C}$ & 29.32 & 3.67 & 27.02 & 5.10 & 24.69 & 3.95 & 21.24 & 7.35 \\
$\mathrm{C}_{1} \mathrm{C}$ & 31.63 & 1.29 & 31.27 & 3.75 & 35.24 & 2.15 & 33.49 & 2.30 \\
$\mathrm{C}_{2} \mathrm{C}$ & 31.57 & 1.27 & 29.98 & 3.18 & 27.64 & 1.66 & 30.14 & 1.11 \\
$\mathrm{C}_{3} \mathrm{C}$ & 6.90 & 3.26 & 10.02 & 1.00 & 6.70 & 2.04 & 5.85 & 3.82 \\
\hline
\end{tabular}


APPENDIX B. ALKANE WR FROM FOURCHON MARSH FIELD SAMPLES FOR FIGURE 1

\begin{tabular}{cccccc}
\hline & & \multicolumn{2}{c}{$8 / 11 / 2011$} & \multicolumn{2}{c}{$11 / 7 / 2013$} \\
Compound & Abbreviation & WR & Stdev & WR & Stdev \\
\hline Decane & C10 & 0.12 & 0.03 & & \\
undecane & C11 & 0.22 & 0.05 & & \\
dodecane & C12 & 0.21 & 0.12 & 0.21 & 0.10 \\
tridecane & C13 & 0.20 & 0.06 & 0.22 & 0.10 \\
tetradecane & C14 & 0.23 & 0.11 & 0.21 & 0.10 \\
Pentadecane & C15 & 0.24 & 0.12 & 0.15 & \\
Hexadecane & C16 & 0.84 & 0.84 & 0.26 & 0.12 \\
Heptadecane & C17 & 0.83 & 0.75 & 0.20 & 0.05 \\
Pristane & PRIS & 0.59 & 0.43 & 0.18 & 0.02 \\
Octadecane & C18 & 0.91 & 0.75 & 0.37 & 0.13 \\
Phytane & PHY & 0.38 & 0.13 & 0.20 & 0.01 \\
n-eicosane & C21 & 0.41 & 0.10 & 0.30 & 0.11 \\
docosane & C22 & 0.41 & 0.21 & 0.38 & 0.08 \\
n-tetracosane & C24 & 0.41 & 0.16 & 0.45 & 0.15 \\
n-hexacosane & C26 & 0.29 & 0.08 & 0.35 & 0.17 \\
n-octacosane & C28 & 0.35 & 0.12 & 0.38 & 0.18 \\
n-tricontane & C30 & 0.37 & 0.17 & 0.40 & 0.20 \\
n-dotricontane & C32 & 0.31 & 0.14 & 0.41 & 0.17 \\
Hopane & HOPANE & 0.26 & 0.07 & 0.21 & 0.01 \\
n-hexatriacontane & C36 & 0.20 & 0.19 & 0.27 & 0.12 \\
\hline
\end{tabular}


APPENDIX C. $\delta^{13} \mathrm{C}$ SIGNATURES IN FOURCHON CORES FROM FIGURE 2.4

\begin{tabular}{cccccccc}
\hline & & \multicolumn{2}{c}{ Bulk Sediment } & \multicolumn{2}{c}{ Roots } & \multicolumn{2}{c}{ Soil } \\
Depth $(\mathrm{cm})$ & Treatment & $\delta^{13} \mathrm{C}$ & St. Dev. & $\delta^{13} \mathrm{C}$ & St. Dev. & $\delta^{13} \mathrm{C}$ & St. Dev. \\
\hline $0-5$ & Extracted & -21.54 & 0.90 & -16.67 & 0.91 & -20.63 & 0.01 \\
$5-10$ & Extracted & -22.13 & 0.22 & -14.02 & 0.06 & -18.66 & 0.06 \\
$10-15$ & Extracted & -18.74 & 0.11 & -13.47 & 0.97 & -17.17 & 0.65 \\
$15-20$ & Extracted & -17.32 & 1.60 & -11.95 & 0.07 & -17.92 & \\
$20-25$ & Extracted & -16.65 & & -12.18 & 0.22 & -16.60 & \\
$0-5$ & Unextracted & -24.85 & 0.75 & -18.12 & 0.71 & -24.56 & 0.01 \\
$5-10$ & Unextracted & -19.10 & 0.02 & -13.23 & 0.20 & -22.29 & 0.17 \\
$10-15$ & Unextracted & -18.63 & & -14.79 & 0.61 & -20.09 & \\
$15-20$ & Unextracted & -18.88 & & -15.53 & 0.24 & -18.89 & \\
$20-25$ & Unextracted & -17.28 & & -14.18 & 0.38 & -17.44 & \\
\hline
\end{tabular}


APPENDIX D. $\delta^{13} \mathrm{C}$ SIGNATURES IN BAY JIMMY CORES FROM FIGURE 2.4

\begin{tabular}{cccccccc}
\hline & & \multicolumn{3}{c}{ Bulk Sediment } & \multicolumn{2}{c}{ Roots } & \multicolumn{2}{c}{ Soil } \\
Depth & Treatment & $\delta^{13} \mathrm{C}$ & St. Dev. & $\delta^{13} \mathrm{C}$ & St. Dev. & $\delta^{13} \mathrm{C}$ & St. Dev. \\
\hline $0-5$ & Extracted & -21.13 & 0.40 & -13.74 & 0.55 & -22.30 & 0.46 \\
$5-10$ & Extracted & -19.62 & 0.10 & -13.58 & 0.78 & -21.61 & 0.58 \\
$10-15$ & Extracted & -19.03 & 0.20 & -18.51 & 3.00 & -20.71 & 0.13 \\
$15-20$ & Extracted & -19.57 & 0.35 & -16.40 & 0.46 & -20.85 & 0.08 \\
$20-25$ & Extracted & -20.01 & 0.21 & -14.88 & 0.67 & -20.32 & 0.36 \\
$0-5$ & Unextracted & -25.94 & 1.21 & -25.25 & 0.98 & -24.93 & 0.18 \\
$5-10$ & Unextracted & -21.11 & 0.28 & -18.63 & 0.65 & -22.06 & 0.23 \\
$10-15$ & Unextracted & -19.56 & 0.07 & -19.18 & 0.64 & -21.42 & 0.25 \\
$15-20$ & Unextracted & -19.42 & 0.39 & -16.00 & 0.54 & -21.01 & 0.21 \\
$20-25$ & Unextracted & -18.73 & 1.52 & -17.02 & 0.38 & -20.93 & 0.26 \\
\hline
\end{tabular}


APPENDIX E. ABBREVIATIONS FOR PAH

\begin{tabular}{cl}
\hline Abbreviation & \multicolumn{1}{c}{ Compound } \\
\hline $\mathrm{C}_{0} \mathrm{~N}$ & naphthalene \\
$\mathrm{C}_{1} \mathrm{~N}$ & C1-naphthalenes \\
$\mathrm{C}_{2} \mathrm{~N}$ & C2-naphthalenes \\
$\mathrm{ACE}$ & acenaphthylene \\
$\mathrm{ACEN}$ & acenaphthene \\
$\mathrm{C}_{0} \mathrm{~F}$ & fluorene \\
$\mathrm{C}_{3} \mathrm{~N}$ & C3-naphthalenes \\
$\mathrm{C}_{0} \mathrm{P}$ & phenanthrene \\
$\mathrm{C}_{1} \mathrm{~F}$ & C1-fluorene \\
$\mathrm{C}_{4} \mathrm{~N}$ & C4-naphthalenes \\
$\mathrm{C}_{0} \mathrm{D}$ & dibenzothiophene \\
$\mathrm{C}_{1} \mathrm{P}$ & C1-phenanthrenes \\
$\mathrm{C}_{2} \mathrm{~F}$ & C2-fluorenes \\
$\mathrm{C}_{1} \mathrm{D}$ & C1-dibenzothiophenes \\
$\mathrm{FLUOR}$ & Fluoranthene \\
$\mathrm{PYR}$ & pyrene \\
$\mathrm{C}_{2} \mathrm{P}$ & C2-phenanthrenes \\
$\mathrm{C}_{3} \mathrm{~F}$ & C3-fluorenes \\
$\mathrm{C}_{2} \mathrm{D}$ & C2-dibenzothiophenes \\
$\mathrm{C}_{1} \mathrm{PYR} / \mathrm{FLUOR}$ & C1-pyrene/fluoranthene \\
$\mathrm{C}_{3} \mathrm{P}$ & C3-phenanthrenes \\
$\mathrm{C}_{3} \mathrm{D}$ & C3-dibenzothiophenes \\
$\mathrm{C}_{0} \mathrm{C}$ & chrysene \\
$\mathrm{C}_{4} \mathrm{P}$ & C4-phenanthrenes \\
$\mathrm{C}_{1} \mathrm{C}$ & C1-chrysenes \\
$\mathrm{C}_{2} \mathrm{C}$ & C2-chrysenes \\
$\mathrm{C}_{3} \mathrm{C}$ & C3-chrysenes \\
\hline &
\end{tabular}




\section{VITA}

Matthew Paul Rodrigue was born and raised in Thibodaux, LA. His parents Clark Joseph Rodrigue, a salesman, and Deborah Waguespack Rodrigue, a pharmacist, were also born in raises in the Thibodaux area. After graduating from Edward Douglas White Catholic High School in Thibodaux, LA in 2008 he moved to Baton Rouge, LA to pursue an undergradauate degree in environmental engineering at Louisiana State University. Upon graduation from LSU in 2012, he decided to continue his engineering education by pursuing graduate degree in civil engineering. As of January 21,2014 , he is certified as a engineer intern by the Louisiana Professional Engineering and land Surveying Board. He expects to graduate in August of 2014 and begin a career in the civil and enviornmental engineering field. 